\title{
THE EFFECTS OF AGE ON MUSCLE LOSS AND TISSUE-SPECIFIC LEVELS OF NF-кB AND SIRT6 PROTEINS IN RATS
}

\author{
A Thesis \\ presented to \\ the Faculty of California Polytechnic State University, \\ San Luis Obispo
}

\begin{abstract}
In Partial Fulfillment
of the Requirements for the Degree

Master of Science in Agriculture with a specialization in Nutritional Science
\end{abstract}

by

Tiev C. LaGuire

May 2013 
(C) 2013

Tiev C. LaGuire

ALL RIGHTS RESERVED 


\section{COMMITTEE MEMBERSHIP}

TITLE:

The effects of age on muscle loss and tissue-specific levels of NF-kB and SIRT6 proteins in rats

AUTHOR:

Tiev C. LaGuire

DATE SUBMITTED: $\quad$ May 2013

COMMITTEE CHAIR: $\quad$ Scott K. Reaves, Ph.D.

Associate Professor

Department of Food Science and Nutrition

California Polytechnic State University, San Luis Obispo

COMMITTEE MEMBER: Louise Berner, Ph.D.

Professor

Department of Food Science and Nutrition

California Polytechnic State University, San Luis Obispo

COMMITTEE MEMBER: Sean Adams, Ph.D.

Research Leader, Obesity \& Metabolism Research Unit

USDA-ARS Western Human Nutrition Research Center

Adjunct Associate Professor

Department of Nutrition

University of California, Davis 


\begin{abstract}
The effects of age on muscle loss and tissue-specific

levels of NF-KB and SIRT6 proteins in rats
\end{abstract}

Tiev C. LaGuire

The objective of this study was to examine the influence of age on food intake, tissue and organ mass and NF-kB and SIRT6 levels in various tissues. The transcription factor, Nuclear Factor Kappa-B (NF-KB), is associated with both catabolic and anabolic pathways of muscle metabolism and may be involved in age-related muscle loss. SIRT6 is a member of the sirtuin family of proteins that function as protein lysine deacetylases and are associated with longevity in a number of organisms. Male Sprague-Dawley rats, aged 6 months (Adult) and 21 months (Old) were fed a commercially available diet for 10-17 days. Old rats consumed less food per body weight (BW) each day than Adult rats $(1.45 \% \mathrm{~g} \mathrm{diet} / \mathrm{g}$ BW vs. $2.4 \% \mathrm{~g} \mathrm{diet} / \mathrm{g} \mathrm{BW})$. However, when intake data were expressed as $\mathrm{g} /$ diet per day there was no significant difference between groups. For skeletal muscle tissue, the average mass of gastrocnemius and soleus (g muscle/g BW) was significantly lower in Old rats. Levels of NF-kB (p65/RelA) and SIRT6 were measured by Western blot analysis in gastrocnemius, tibialis anterior, quadriceps, soleus, lung, heart, kidney and liver. NF-KB levels were higher in gastrocnemius of Old rats compared to Adult rats. No significant age-specific differences in SIRT6 protein levels were noted in the tissues examined. Interestingly, when examined independent of age, levels of SIRT6 were significantly different between certain tissues. Data from this study suggest that age affects muscle loss and NF-KB in a tissue-specific manner. Furthermore, these findings indicate tissue-specific but not age-specific differences in SIRT6 protein levels.

Keywords: Rat; NF-кB; SIRT6; muscle atrophy; proteolysis. 


\section{ACKNOWLEDGMENTS}

\section{United States Military Personnel}

I thank all of the troops for their dedicated service so that I may pursue my goals and dreams in life.

\section{McOmie and Hull fellowships}

The financial support given allowed me to pursue my Masters education. Without it, I would not have been able to obtain my graduate degree.

\section{Sean Adams, Ph.D.}

Thank you for serving on my committee so I may obtain my Masters Degree. Your time and effort are much appreciated.

\section{Peggy Papathakis, Ph.D., R.D. and Lisa Nicholson, Ph.D., R.D.}

Thank you for being so unselfish and for having faith that I was qualified enough to help teach Clinical and Introductory Nutrition. I learned more than I taught.

\section{Louise Berner, Ph.D.}

Thank you for serving on my committee so I may obtain my Masters Degree. Your time and effort are much appreciated.

Thank you for believing in my ability to teach our undergraduate students. It was one of the best experiences of my life.

\section{Mom and Dad}

Thank you for everything. I wouldn't be here without you.

\section{Scott Reaves, Ph.D.}

Thank you for all of your support and guidance on my research, writing, and teaching. I've learned more than I ever anticipated was possible. You will never know the friend you have been to me over the years. Thank you.

\section{God}

I thank the Heavenly Father above that I was blessed to be born in a country that allows women to pursue careers in the scientific field. Thank you for guiding me down my life's path. Even when I hit bumps in the road, thank you for providing soft landings. Thank you for blessing me with my health, those few closest to my heart, and the abilities to succeed in science. And thank you for the opportunities for said success. Finally, thank you for giving me common sense - I know you didn't bless everyone with it, but thank you for letting me be one of the fortunate receivers.

There but by the grace of God go I. 


\section{TABLE OF CONTENTS}

LIST OF TABLES ---

LIST OF FIGURES -- --

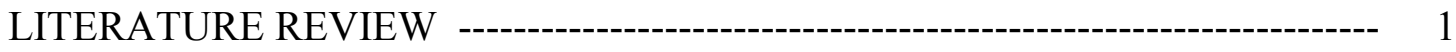

Statistics related to the older population in the U.S. ------------------- 1

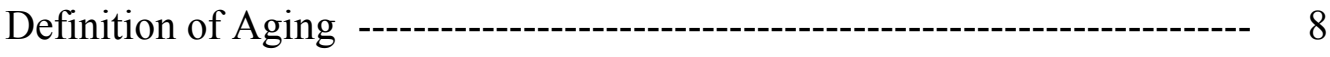

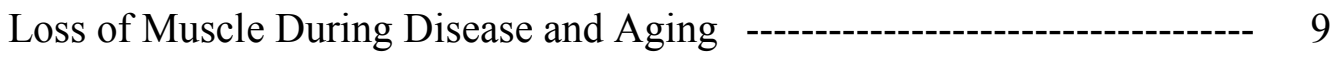

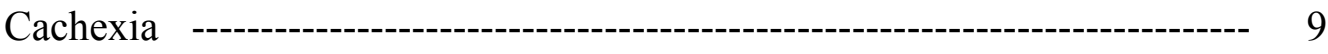

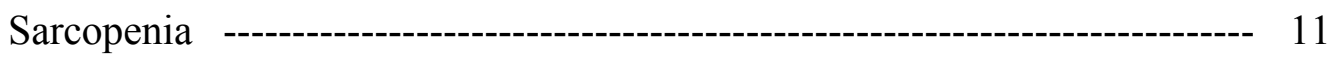

Putative Causes and Theories of Aging --------------------------------- 13

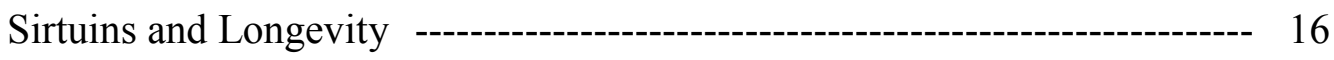

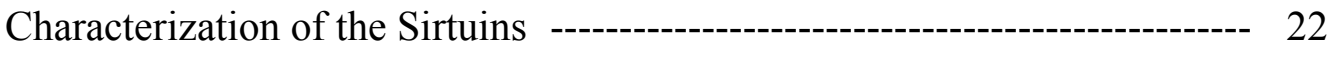

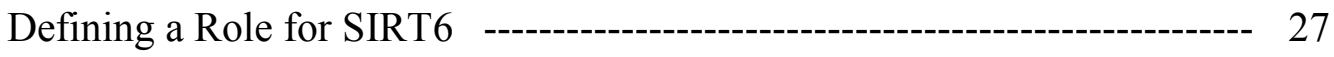

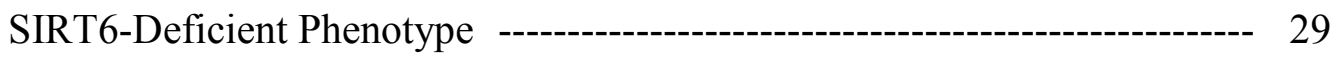

SIRT6 Over-expression and Effects on Metabolism and Lifespan ---------- 31

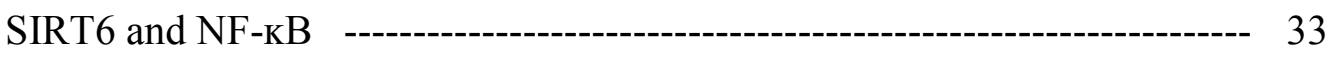

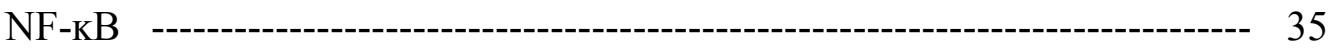

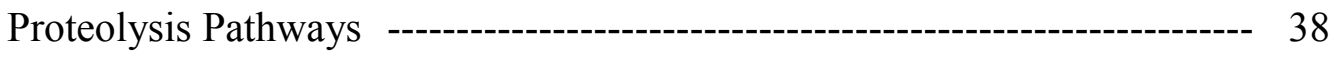

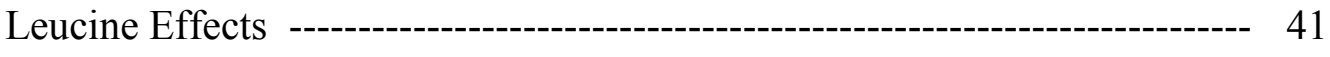

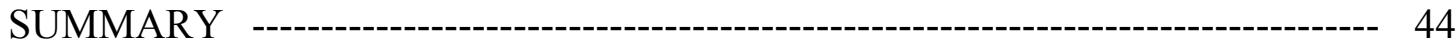

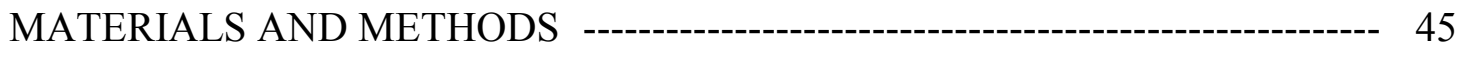

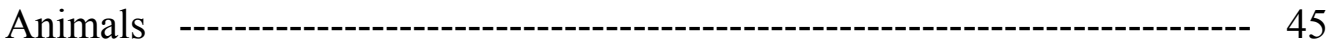




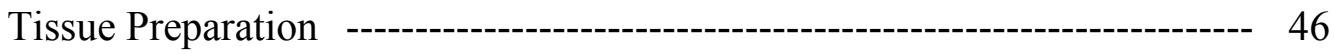

SDS PAGE and Transfer to Nitrocellulose Membrane ---------------------- 46

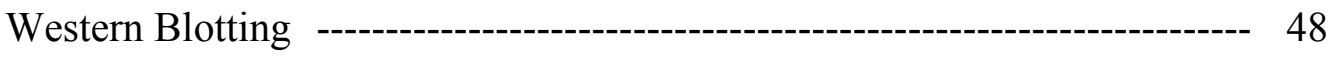

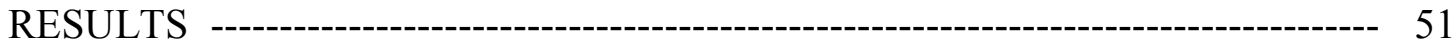

Body and Tissue Weights

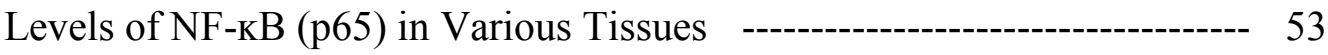

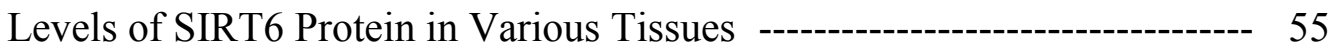

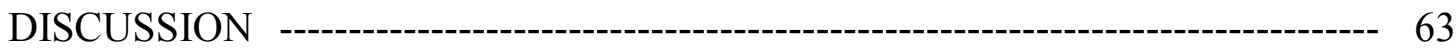

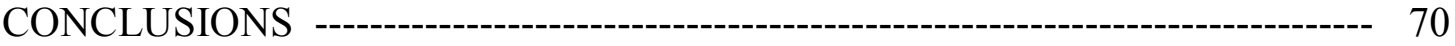

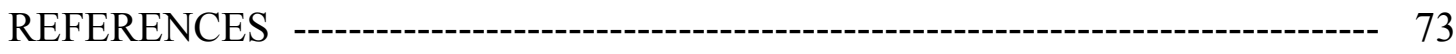




\section{LIST OF TABLES}

Table $\quad$ Page

1 Diet Composition - -

2 Average Body Weight \& Food Intake of Adult and Old Rats -------------- 51

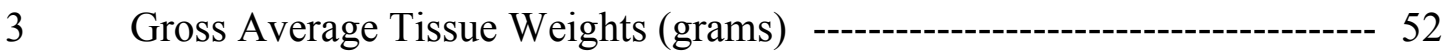

4 Average Tissue Weight Per Body Weight (as percentages) ------------------ 52 


\section{LIST OF FIGURES}

Figure

1 Average diet scores for the population 65 and older, by age group, for years 2007-2008.

2 Percentage of people 45 and over who reported participating in leisuretime aerobic and muscle-strengthening activities that meet the 2008 Federal physical activity guidelines, by age group, selected years 1998-2010.

3 Percentage of population age 65 and over who are obese, by sex and age group in the selected years of 1988-2010.

4 Modification of histones by lysine acetylation.

5 SIRT1 activation alters hepatic glucose and fatty acid metabolism by deacetylation of PGC- $1 \alpha$.

6 SIRT1 binds and deacetylates FOXO3 to affect cell cycle arrest.

7 Effects of a high fat diet on SIRT3 and associated factors in mice.

8 The effects of caloric restriction on SIRT3 activity, mitochondrial biogenesis, and longevity.

9 SIRT4 inactivates glutamate dehydrogenase (GDH) by ribosylation.

The result tends to be decreased insulin stimulation.

10 SIRT5 activates carbamoyl phosphate synthetase 1 (CPS1) by deacetylation.

$11 \quad$ NF-kB signaling pathways.

12 Activation of NF-KB p65/p50 heterodimer and translocation to $\mathrm{NF}-\mathrm{KB}$ response elements in nucleus.

13 Flowchart of experimental design.

14 Tissue levels of NF-kB (p65) in adult (age 6 months) and old (21 months) rats. 
Figure

15 NF-кB (p65) protein levels in specific tissues of adult (age 6 months) vs. old (age 21 months) rats.

16 NF-kB (p65) protein levels in specific tissues of adult (age 6 months) vs. old (age 21 months) rats.

17 Tissue levels of SIRT6 in adult (age 6 months) and old (age 21 months) rats.

18 SIRT6 protein levels in specific tissues of adult (age 6 months) vs. old (age 21 months) rats. 60

19 SIRT6 protein levels in specific tissues of adult (age 6 months) vs. old (age 21 months) rats. 


\section{LITERATURE REVIEW}

Statistics related to the older population in the U.S.

The proportion of the U.S. population that is considered to be elderly is increasing at a disproportionate rate relative to other age groups. One of the main reasons this is occurring is because of the "Baby Boomers" reaching this age group. Baby Boomers are defined as the population of Americans that were born between 1946 and 1964 (Administration on Aging, 2012). In 2011, the oldest members of this cohort turned 65 years of age and so the first part of an 18-year wave is reaching 65 years of age. Major advances in science and medicine have consistently extended the life span of Americans, and thus the combination of factors has led to a large percentage increase in older Americans relative to other age groups (Administration on Aging, 2012).

Since 1900, the percentage of Americans 65+ has more than tripled (from $4.1 \%$ in 1900 to $13.1 \%$ in 2010), and the number of persons in this age group has increased almost thirteen times (from 3.1 million to 40.4 million). This trend has continued in more recent years. In the year 2010, approximately 40 million Americans $(13 \%$ of the population) were 65 years of age or older (Administration on Aging, 2012). This is expected to be $20 \%$ by the year 2030 , or approximately 72.1 million persons. The older population itself is increasingly older and this is adding to the numbers in this group. For example, in 2010, the 65-74 age group was 10 times larger than in 1900. Numbers of individuals older than 74 years of age have also increased dramatically (Administration on Aging, 2012). In 2009, persons reaching age 65 had an average life expectancy of an 
additional 18.8 years (20.0 years for females and 17.3 years for males). A child born in 2009 is expected to live 78.2 years. This is approximately 30 years longer than a child born in 1900. Much of this increase occurred because of reduced death rates for children and young adults. However, the period of 1990-2007 also has seen reduced death rates for the population aged $65-84$, especially for men. Death rates decreased by $41.6 \%$ for men aged 65-74 and by 29.5\% for men aged 75-84 during 1990-2007 (Administration on Aging, 2012).

Having 1 in 5 Americans in the age group of 65 years and older could present a multitude of challenges, especially if these individuals are suffering with disabilities or poor health. This high number of individuals reaching 65 years of age will put a strain on support systems like this country has never seen before. There are a number of government agencies that focus on the health and well-being of older Americans. One of these agencies is known as the Administration on Aging (AoA) and one of their objectives is to consolidate information from numerous other agencies. One item on the AoA website is a report titled, "Older Americans 2012." The report was prepared by the Federal Interagency Forum on Aging-Related Statistics to provide a comprehensive source of information on key indicators of well-being. The report includes 37 indicators that are grouped into five sections: Population, Economics, Health Status, Health Risks and Behaviors, and Health Care. The section on Health Risks and Behaviors includes statistics and information on the indicators vaccinations, mammography, diet quality, physical activity, obesity, cigarette smoking, air quality, and use of time. Although each of these indicators could be considered relevant to the well-being of older persons it is unfortunate that body composition and lean body mass were not included as indicators 
because they significantly affect health. However, there is some very interesting data about diet, physical activity, and obesity in the report and the highlights are shown and briefly discussed below. Information on the average diet of those 65 years and over is shown in Figure 1. Scores are based on The Healthy Eating Index-2005. The index has 12 components, and a higher score indicates a higher quality diet. Intakes equal to or better than the standards set for each component are assigned a maximum score of 100 percent. For the nine adequacy components (e.g., total fruit), no intake gets zero percent, and scores increase up to 100 percent as the intakes increase toward the standard. The three moderation components (e.g., sodium) are scored in reverse; that is, excessively high intakes get zero percent and as intakes decrease toward the standard, scores increase up to 100 percent. Scores are averages across all American adults based on usual dietary intake.

As shown in Figure 1, in 2007-2008 the average dietary intake of older persons met the standard (shown as $100 \%$ ) in only three of the dietary component categories. These were the categories of whole fruits, total grains, and meats/beans. Intakes for the other nine categories were below recommendations. These data suggest that significant improvements in nutrient intake for older Americans could be accomplished by increasing their intake of whole grains, dark green and orange vegetables and legumes, and fat-free or low-fat milk products. In addition, the intake of foods and beverages with sodium, solid fats, alcohol, and added sugars should be reduced. It stands to reason that improving the dietary intake of older Americans could be an effective method to improve their health. 


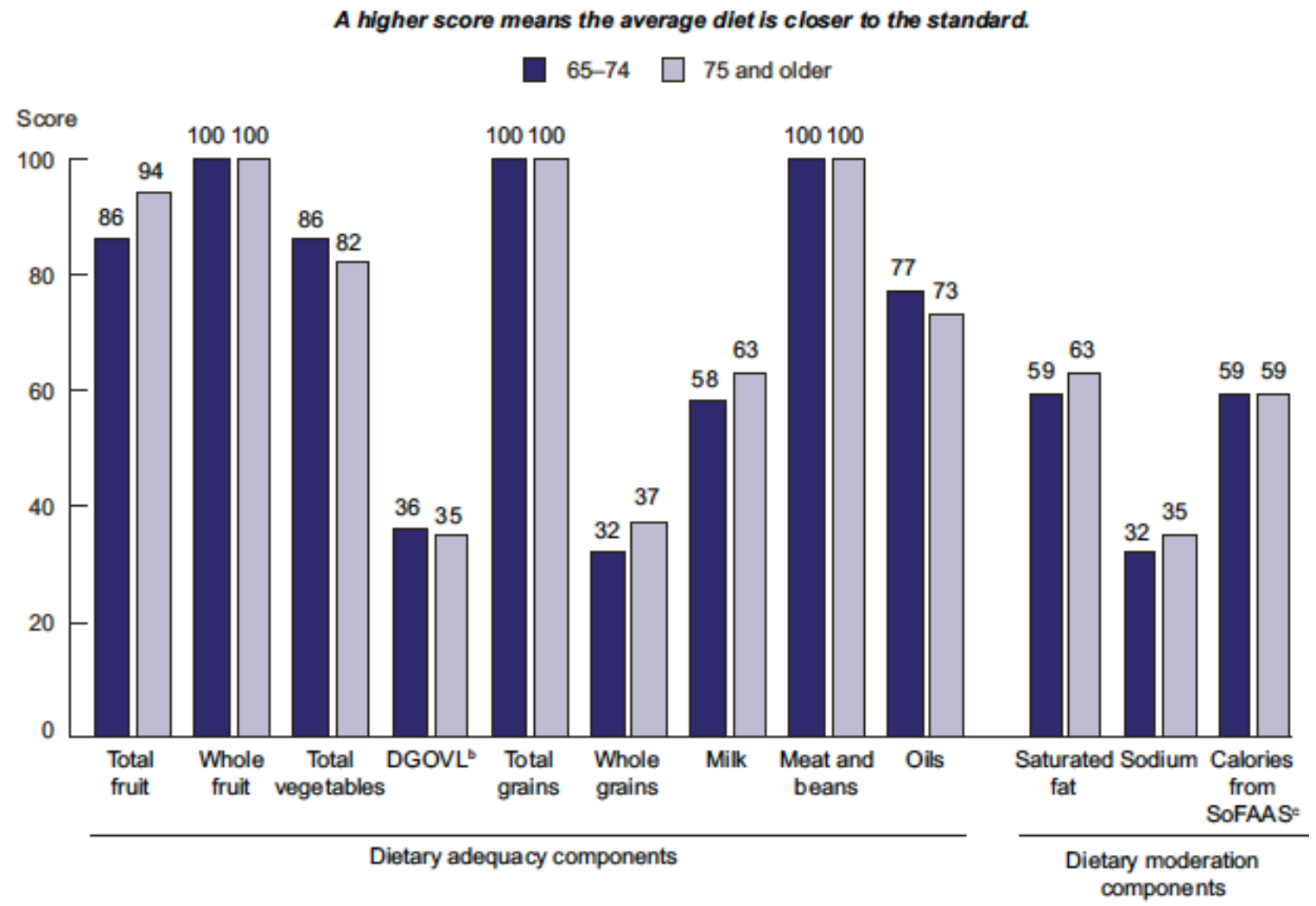

Figure 1: Average diet scores for the population 65 and older, by age group, for years 2007-2008. Scores, reported as percentages in this chart, are average Healthy Eating Index-2005 scores and not the percentages of individuals who meet the diet quality standards. ${ }^{\mathrm{b}}$ Dark green and orange vegetables and legumes. ${ }^{\mathrm{c}}$ Solid fats, alcoholic beverages, and added sugars. Reference population: These data refer to the resident noninstitutionalized population. SOURCE: Centers for Disease Control and Prevention, National Center for Health Statistics, National Health and Nutrition Examination Survey, 2007-2008 and U.S. Department of Agriculture, Center for Nutrition Policy and Promotion, MyPyramid Equivalents Database 2007-2008 (preliminary), Healthy Eating Index-2005. Figure from: Administration on Aging, "Older Americans 2012."

Another way to improve the health of older Americans would be to increase their physical activity because many do not engage in regular physical activity. In an effort to promote physical activity, the Office of Disease Prevention and Health Promotion and the President's Council on Fitness, Sports and Nutrition released the 2008 Physical Activity Guidelines (health.gov/paguidelines/guidelines/). The guidelines include a chapter for 
Active Older Adults for those aged 65 years and older. The guidelines acknowledge that fitness levels vary widely in this age group and state "the chapter focuses on physical activity beyond baseline activity" and it is evident that the guidelines represent a rigorous expectation.

The basic guidelines for substantial health benefits are that adults perform at least 150 minutes ( 2 hours and 30 minutes) a week of moderate-intensity, or 75 minutes (1 hour and 15 minutes) a week of vigorous-intensity aerobic physical activity, or an equivalent combination of moderate- and vigorous-intensity aerobic activity. Aerobic activity should be performed in episodes of at least 10 minutes, and preferably, it should be spread throughout the week. The 2008 guidelines also recommend that adults perform muscle-strengthening activities that are moderate or high intensity and involve all major muscle groups on two or more days a week, because these activities provide additional health benefits (U.S. Department of Health and Human Services, 2008).

As mentioned above, these would appear to be quite rigorous for adults 65 years o age and older. However, it does state that for "adults aged 65 and older who are fit and have no limiting chronic conditions, the guidance in this chapter is essentially the same as that provided in Chapter 4 - Active Adults." Chapter 4 provides guidance for most men and women aged 18 to 64 years of age. So, essentially many of the HHS physical activity guidelines for a person older than 65 without limiting chronic conditions are the same as an 18 year old. This seems to be an unrealistic expectation for older adults and sheds light on why such a large percentage of adults 65 years and older do not meet these physical activity guidelines (Figure 2). However, it also seems likely that not enough adults in this age category are exercising at optimal levels. 
As Figure 2 indicates, most older Americans do not perform adequate amounts of physical activity. In 2010 only about 11 percent of people age 65 and over reported participating in leisure-time aerobic and muscle-strengthening activities that met the 2008 Federal physical activity guidelines. Unfortunately, the percentage of older people meeting the physical activity guidelines decreased with age, ranging from 14 percent among people age 65-74 to 4 percent among people age 85 and over. There were also gender and ethnicity specific differences as men age 65 and over were more likely than women in the same age group to meet the physical activity guidelines (14 percent and 8 percent, respectively, in 2010). Older non-Hispanic Whites reported higher levels of physical activity than non-Hispanic Blacks (12 percent compared with 5 percent). Fortunately, the trend seems to be improving because the percentage of older people meeting the Federal physical activity guidelines increased over time. In 1998, about 6 percent of people age 65 and over met the guidelines, compared with 11 percent in 2010. However, significant progress needs to be made if the health and well-being of seniors is to be improved by physical activity.

Obesity is another key indicator of health that was included in the Older Americans 2012 report. Obesity is associated with premature death and a number of chronic diseases. Data from the report are shown below in Figure 3. As with other age groups, the percentage of obese persons in the over 65 group has increased in recent years. Between 1988-1994 approximately $22 \%$ of persons over 65 were obese but that increased to $38 \%$ of in 2009-2010. This represented increases in both genders.

In summary, there has been a significant increase in the segment of our population that is 65 years of age and older in the U.S. in recent years and it will likely continue to 
increase for years. This will pose a tremendous burden on the support systems specific to the elderly. Data related to the health of this population is extremely important if we are going to optimize our ability to support their well-being and help them to live quality lives in their older years. Some data already indicates there are areas that appear to be logical targets for improvement. For example, it appears that programs should focus on improving the diet, increasing physical activity level, and reducing the prevalence of obesity would help seniors live longer healthier lives.

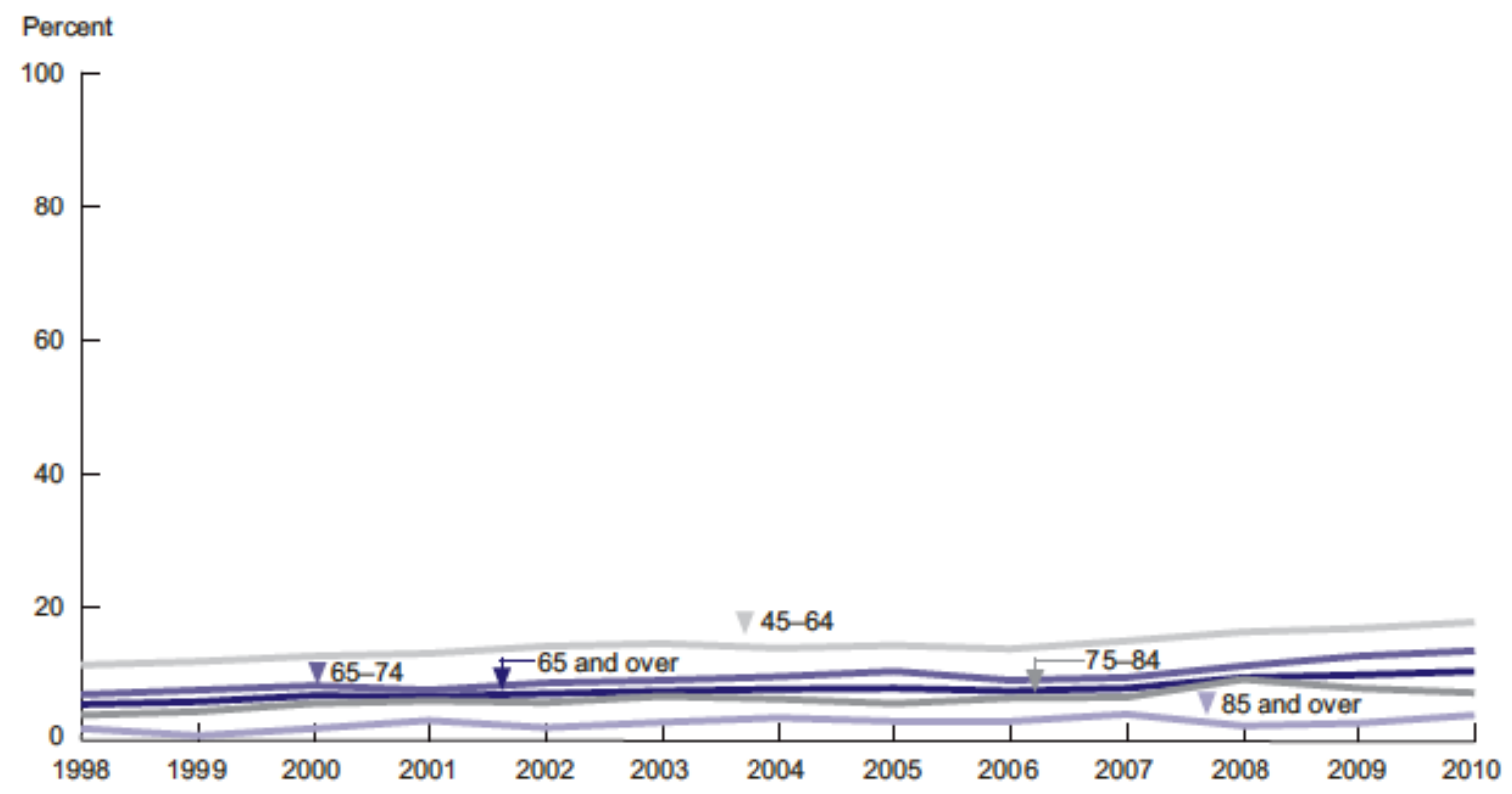

Figure 2: Percentage of people 45 and over who reported participating in leisuretime aerobic and muscle-strengthening activities that meet the 2008 Federal physical activity guidelines, by age group, selected years 1998-2010. NOTE: This measure of physical activity differs from previous editions of Older Americans. The measure reflects the 2008 Federal physical activity guidelines for Americans (available from: http://www.health.gov /PAGuidelines/). The measure shown here presents the percentage of people who fully met both the aerobic activity and muscle-strengthening guidelines. Reference population: These data refer to the civilian non-institutionalized population. SOURCE: Centers for Disease Control and Prevention, National Center for Health Statistics, National Health Interview Survey. Figure from: Administration on Aging, Older Americans 2012. 


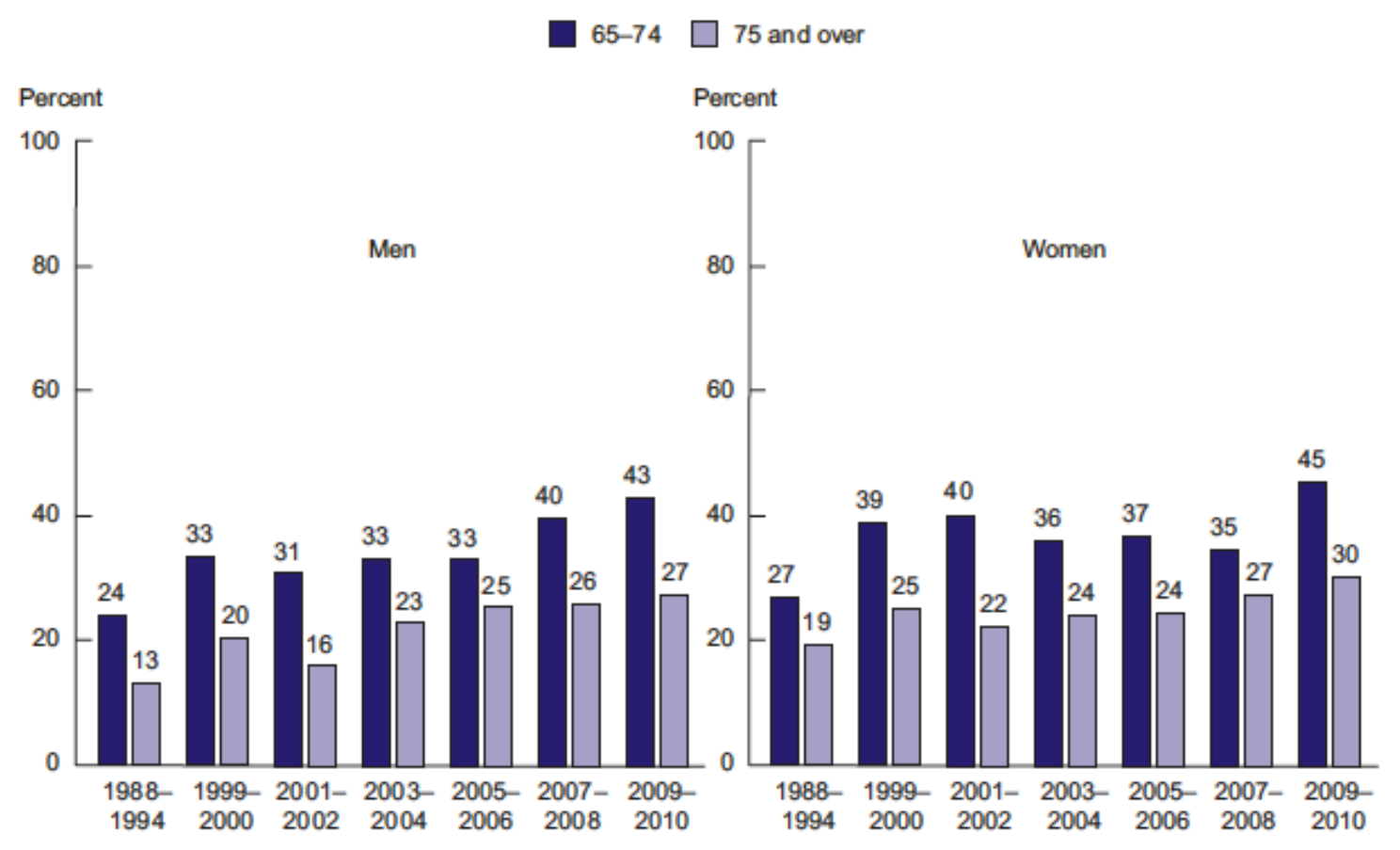

Figure 3: Percentage of population age 65 and over who are obese, by sex and age group in the selected years of 1988-2010. Data are based on measured height and weight. Height was measured without shoes. Obese is defined by a BMI of 30 kilograms/ meter ${ }^{2}$ or greater. The percentage of people who are obese is a subset of the percentage of those who are overweight. See data source for the definition of BMI. Reference population: These data refer to the civilian non-institutionalized population. SOURCE: Centers for Disease Control and Prevention, National Center for Health Statistics, National Health and Nutrition Examination Survey. Figure from: Administration on Aging, "Older Americans 2012."

\section{Definition of Aging}

There are numerous ways to define aging. Aging may be defined as the biological impairment of normal function probably as a result of changes made to cells and structural components such as bone and muscle. Aging can also be thought of as the accumulation of changes in a person or organism over time and it must be considered that changes can be either advantageous or detrimental depending on how early or late it 
occurs in the lifespan. For example, during the developmental period many changes from age are advantageous and necessary for optimal health and survival. Biological aging is also sometimes referred to as "senescence" and is considered the changes in the biology of an organism after it reaches maturity. In fact, the word senescence is derived from the Latin word senescere, which means "to grow old." In humans, it is a multidimensional process that includes biological, functional, and social change. There are numerous theories as to how and why the changes occur and the study of aging is the focus of much research as scientists attempt to determine if there are ways to slow, avoid, or even reverse the effects of aging.

\section{Loss of Muscle During Disease and Aging}

In general, the loss of muscle is a common occurrence in aging and many diseases. In some instances muscle loss also occurs because of disease and aging simultaneously. Muscle loss associated with disease is often referred to as cachexia while muscle loss as part of aging is often termed sarcopenia. Prevalence and a brief description of cachexia and sarcopenia are in the following sections.

\section{$\underline{\text { Cachexia }}$}

The term cachexia is derived from Greek terms meaning "bad condition." Cachexia is associated with various disease conditions that include involuntary muscle loss. A further definition of cachexia is a syndrome with numerous causes that leads to 
loss of body weight, fat and muscle because of increased protein catabolism (Anker and Sharma 2002). Common diseases associated with cachexia include cancer, chronic heart failure and chronic obstructive pulmonary disease. The tissue loss of cachexia compromises the quality of life by reducing strength and endurance and it likely increases the risk of acquiring other illnesses and diseases. This results in a very poor prognosis for those afflicted with cachexia (Glass and Roubenoff, 2010).

Cancer cachexia is present in most types of cancer and can be the factor that eventually leads to mortality. The loss of body mass of cachexia is due to a variety of factors including tumor-derived factors, anorexia, endocrine changes and alterations in signaling molecules such as the cytokines. Probably the most well studied cytokine related to cachexia is tumor necrosis factor- $\alpha(\mathrm{TNF}-\alpha)$. During its initial characterization, this cytokine was found to be the same as a previously discovered protein, called cachectin, that was able to induce cachexia. TNF- $\alpha$ induces a variety of effects including induction of skeletal muscle catabolism via the ubiquitin-proteasome system (UPS) (Mitch and Price, 2001). Other cytokines are also involved and the combination of cytokine alterations and other factors can result in body mass loss even in the absence of anorexia. Unfortunately, there are no approved agents for the treatment of cancer cachexia so this represents a significant void in cancer patient care. 


\section{$\underline{\text { Sarcopenia }}$}

The term sarcopenia refers to the loss of muscle mass and function associated with aging (Rosenberg, 1997). Although its etiology is not fully defined there are a number of factors that are part of old age and appear to contribute to sarcopenia. Some of the major factors include an increase in inflammatory cytokines (Alemán et al., 2011; Visser et al., 2002), decreased physical activity (Klitgaard et al., 1990), bedrest (Kortebein et al., 2007), and oxidative stress and hormonal alterations (Kley et al., 2007; Malafarina et al., 2012). In addition to these factors, dietary intake has also been shown to play a vital role in sarcopenia. Studies have shown that inadequate food intake may be one of the major causes as inadequate protein intake increases the rate of loss of lean body mass as the body responds metabolically to compensate (Andrews et al., 2006). Indeed, numerous studies have indicated that the Recommended Dietary Allowance (RDA) of $0.8 \mathrm{~g} / \mathrm{kg} /$ day for protein intake is not adequate for the elderly. Research suggests it should be adjusted to approximately $1.25-1.5 \mathrm{~g} / \mathrm{kg} /$ day to promote better overall health and decrease loss of lean mass in older individuals (Wolfe et al., 2008; Evans, 1995). Therefore, protein intake and/or improved dietary protein quality should be examined in persons that may suffer from sarcopenia as at least one means to protect against the condition.

Unlike cachexia, sarcopenia is not considered to be a disease. Even though a widely accepted definition of sarcopenia has not been defined, in general, groups working to define it agree that the definition should include criteria specific for both muscle and concomitant loss of function. For example, the Society on Sarcopenia, Cachexia, and 
Wasting Disorders has defined it based on results from a walking test when a person walks $<1 \mathrm{~m} / \mathrm{sec}$, or less than 400 meters covered in six minutes with a lean body mass $\leq 7.23 \mathrm{~kg} / \mathrm{m}^{2}$ in men and $\leq 5.67 \mathrm{~kg} / \mathrm{m}^{2}$ in women as measured by Dual-energy X-ray Absorptiometry (DXA) (Muscaratoli et al., 2010). Other groups have also defined sarcopenia but with slightly different criteria and this had led to discrepancies in estimations of prevalence and effectiveness of treatments. However, there is no doubt that significant numbers of persons are affected throughout the world. Melton et al. estimated the prevalence to be between $13-24 \%$ in adults over 60 years of age and more than $50 \%$ in those 80 years of age and older (Melton et al., 2000). A different study estimated the prevalence at $5-13 \%$ for those $60-70$ years of age and $11-50 \%$ in those aged 80 years and above (Von Haehling et al., 2010). Estimates put the number of sarcopeniarelated disability in the $>60$-year-old population to be between 5 and $10 \%$ and this translates to about 7-10 million patients in the U.S. and European Union. In the U.S., it has been estimated that direct healthcare costs attributable to sarcopenia are at $\$ 18.5$ billion per year (Janssen et al., 2004). Obviously, it would be advantageous from both the personal and healthcare system perspectives if more effective treatments could be developed to decrease the incidence and detrimental effects of sarcopenia.

Up to this point exercise, particularly resistance exercise, is the only proven treatment for preventing or reducing muscle wasting. However, there are inherent difficulties in prescribing exercise to large populations and especially in the elderly. Exercise programs in the elderly requires trained persons to instruct as well as adequate and appropriate facilities and equipment to support the regimens. It also requires that the elderly person is motivated not only to start but also to consistently partake in the 
program. Unfortunately the persons affected often would not enjoy exercise and that might be why they have the condition in the first place. Moreover, they may be suffering from physical pain and ailments that make the exercise regimen difficult to perform. So, when these aspects are considered with exercise regimens it stands to reason that the discovery of effective dietary or pharmacological treatments that minimize incidence or effects of sarcopenia would be highly advantageous. Unfortunately, this has also proven to be problematic. Future work must also continue to define and describe intracellular molecular factors that regulate processes related to aging. Elucidating details of intracellular events is a crucial part of understanding aging and evaluating effects of certain treatment strategies.

\section{Putative Causes and Theories of Aging}

Because senescence affects every human being, there is a tremendous amount of research examining the process of aging. As findings have accumulated, a number of models and theories have developed and have been tested in an attempt to explain aging. Some of the theories are based on evolutionary events and involve the accumulation of changes to an organism's makeup over time. Some of the theories of aging involve specific physiologic and/or cellular alterations that occur and may explain why an organism such as humans age during their lifetime. A number of the physiologic and cellular theories are identified and briefly explained below.

The telomere theory of aging hypothesizes that normal somatic cells have a finite lifespan that is determined by the length of their telomeric DNA. Telomeric DNA 
consists of long repeating sequences that are located at the ends of chromosomal DNA and are added and maintained by an enzyme known as telomerase (Artandi, 2006). Cells typically seem to lose telomeric DNA as they divide and when this DNA reaches a specific shortened length the cells tend to enter senescence and stop dividing. Indeed, this is an intriguing theory as the promotion of telomerase activity and re-lengthening of telomerase activity in human senescent cells allowed the cells to exit senescence and replicate (Vaziri and Benchimol, 1998). Research related to this theory has continued and this is still considered to be a relevant theory of aging.

The autoimmune theory of aging states that the body later in life begins to produce autoantibodies against its own tissues and/or there are time-acquired deficits in T-cell function (Walford, 1969; Kent, 1977; Pawelec et al., 2004). These changes make the body susceptible to infections, cancer, and other chronic diseases, especially autoimmune diseases. The role of autoimmune aberrations in aging, like many other theories, remains to be determined. However, there is indeed strong evidence that the immune system is involved in the aging process and this has led to the term "inflammaging" to describe the process. In this model, innate immunity seems to be activated and this causes systemic inflammation that alters both systems and cellular processes and these contribute to the aging phenotype (Salminen et al., 2008). One of the key molecules in this process appears to be the well-known, well-described transcription factor complex known as NF-kB. This is one of the most studied theories in aging and will be discussed in greater detail in the subsequent section on NF-KB.

Considerable attention has also been placed on epigenetics and aging. The term epigenetics was coined to explain alterations related to genes and their expression but that 
do not directly alter the nucleotide sequence of the gene. The alterations include structural modifications to chromatin that regulate the transcription of certain genes. These modifications include DNA-methylation, histone acetylation, imprinting, RNAinterference, gene silencing, and paramutations (Allis et al., 2007). Epigenetics plays a role in regulating numerous genes that have been shown to have roles in aging and shorten lifespan. One of the best examples of how epigenetics is related to aging is the gene in yeast known as SIR-2. Genetic studies showed caloric restriction increased longevity and that SIR-2 was involved and subsequently it was shown that SIR-2 is a member of a family of genes now known as the SIRTs (sirtuins) that are expressed in a wide variety of organisms including humans. Mechanistic studies subsequently showed that SIRTs are deacetylases that modify chromatin structure to modulate transcription of genes via epigenetics. The SIRTs and epigenetics are one of the most researched aging theories and will be discussed in greater detail in a later section.

When caloric restriction was first found to increase longevity in rats (McCay et al., 1939), researchers began to perform follow up studies designed to determine the mechanisms involved. Eventually a theory developed that suggested that the reason caloric restriction promoted longevity was because fewer free radicals (also known as reactive oxygen species (ROS)) were formed due to less metabolism of energy producing substrates. This is now known as the free radical theory of aging of Harman and it proposes that during aging macromolecules are oxidized and accumulate to compromise cellular functions and shorten lifespan (Harman, 1968). The free radicals damage cellular membranes, proteins and DNA, as well as other molecules, and it was hypothesized that the damage to mitochondria was especially harmful and was linked to lifespan (Harman, 
2006).

However, recent studies have indicated there are shortcomings to the free radical theory of aging. For example, nutritional and genetic strategies that increase antioxidants typically have not resulted in an increased lifespan. For example, when the results of nineteen clinical trials with vitamin E supplementation were compiled there appeared to be no reduction in mortality (Miller et al., 2005). Supplementation with vitamin $\mathrm{C}$ also appeared to have no significant benefit to lifespan extension (Bjelakovic et al., 2007). Studies using molecular techniques to increase levels of key anti-oxidant enzymes had mixed results with some having no effect while others increased lifespan of mice (Perez et al., 2009; Mitsui et al., 2002; Schriner et al., 2005). Another challenge to the free radical theory of aging is that of exercise. In general, exercise increases free radical production (Powers and Jackson, 2008) and cellular damage and yet exercise generally enhances human aging (Nakamura et al., 1996) and extends lifespan in mice (Navarro et al., 2004) and rats (Holloszy et al., 1985). Overall, there is validity in the free radical theory of aging but it does not account for all aspects of the aging process.

\section{$\underline{\text { Sirtuins and Longevity }}$}

In the late 1980's, a group of genes was first described in the yeast Saccharomyces cerevisiae as having a role in determining yeast mating types. The genes were called the SIR (ilent information regulator) genes because they could transcriptionally repress the silent mating loci known as HML and HMR (Ivy et al., 1986; Rine \& Herskowitz, 1987). Additional roles were also characterized for the SIR genes 
but in the late 1990's a breakthrough was made that linked one of the SIR genes to increased lifespan (longevity) in yeast and subsequent research into their functions increased exponentially. The breakthrough was in 1999 when Kaeberlein et al. showed that the yeast SIR-2 gene decreased lifespan when it was mutated but increased lifespan when the wildtype SIR-2 expression was increased (Kaeberlein et al., 1999). As mentioned previously, years ago a study (McCay et al., 1939) showed that caloric restriction $(\mathrm{CR})$ in rats extended their lifespan. Additional studies in several species and organisms indicated that CR extends their lifespans as well. A follow-up study, by the same research group that showed SIR-2 increased longevity, provided evidence that caloric restriction could not increase longevity in SIR-2 mutant yeast. This indicated that SIR-2 was indeed required for the increased lifespan with caloric restriction (Lin et al., 2000). Subsequent analysis indicated SIRT1 is the mammalian homolog of the yeast SIR-2. It has since been determined that mammals express seven homologs of yeast SIR2 and they are known as Sirtuins 1-7 (Taylor et al., 2008). However, it has been shown that SIRT1 has the closest structural and sequence similarities to SIR-2, hence it received the most attention in the initial phase of research in mammalian sirtuins.

There are now a multitude of details known about the Sirtuins. The Sirtuins are NAD-dependent deacetylases that remove acetyl groups from amino acid residues of histone proteins. SIR-2 and SIRT1 were the first in the group to be identified as a deacetylase (Imai et al., 2000). Acetylation of lysine residues is a common posttranslational modification often used in epigenetic regulation (Figure 4). By deacetylating histones the SIRTs alter chromatin structure and modulate expression of genes involved in a wide range of activities and different tissues. 
Recent work has indicated that SIRTs also deacetylate molecules that are not histones. For example, SIRT1 deacetylates cytosolic acetyl-CoA synthetase (Hallows et al., 2006), a key enzyme in fatty acid synthesis. SIRT1 also deacetylates several transcription factors including PGC-1 $\alpha$ (Rogers et al., 2005). In this process, fasting induces SIRT1 protein in the liver which then interacts with and deacetylates PGC-1 $\alpha$ which induces gluconeogenic genes and hepatic glucose output. In addition, the deacetylation of PGC-1 $\alpha$ by SIRT1 caused repression of hepatic glycolysis in fasting (Rodgers et al., 2005) (Figure 5). These findings implicate SIRT1 as a key regulator of energy homeostasis in addition to its originally described roles. Like SIRT1, AMPactivated protein kinase (AMPK) responds to nutritional and metabolic cues, mostly by sensing AMP levels, and can affect the activity of a variety of processes related to energy metabolism (Canto et al., 2009). Overall, AMPK responds to increases in cellular AMP by increasing the activity of pathways / processes that produce ATP production while decreasing processes that require ATP (Canto et al., 2009). A significant number of studies have shown that SIRT1 and AMPK often work in a coordinated fashion to regulate energy-related pathways (Figure 5) (Canto el al., 2009; Fulco and Sartorelli, 2008; Price et al., 2012; Choi et al., 2013). 


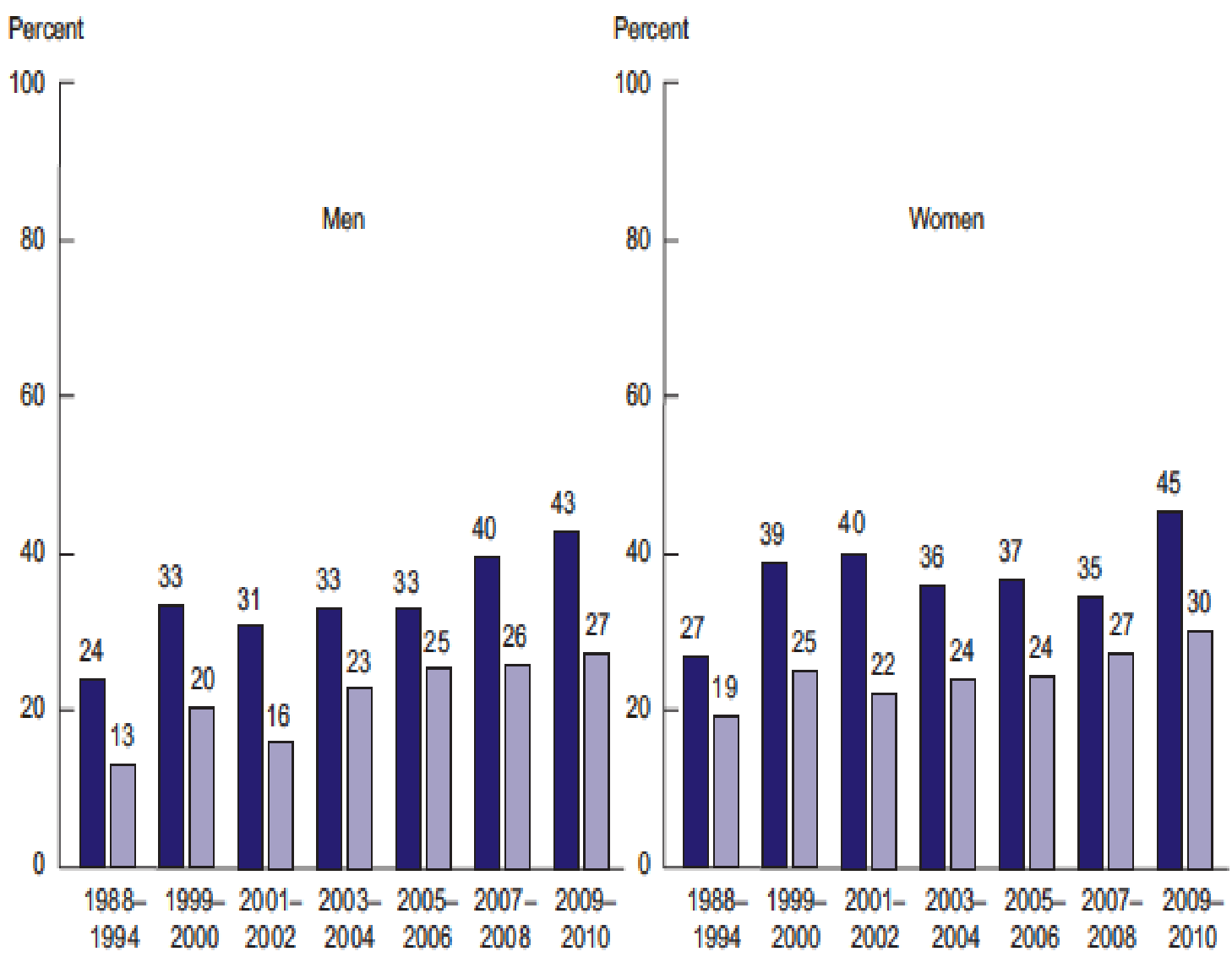

Figure 4: Modification of histones by lysine acetylation. The modification relaxes the chromatin structure and facilitates gene expression. SIRTs reverse the process through deacetylation and repression of gene expression. 


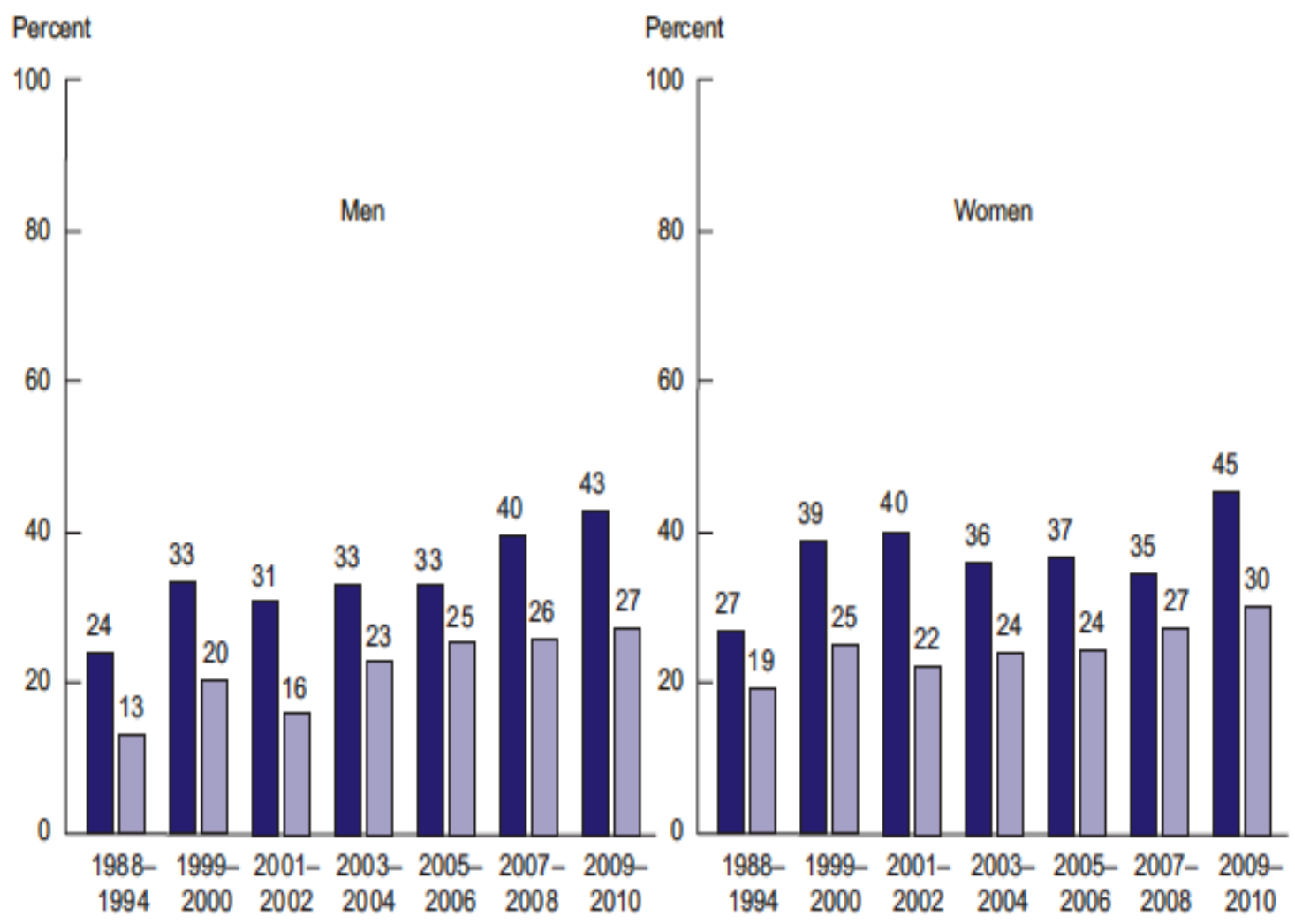

Figure 5: SIRT1 activation alters hepatic glucose and fatty acid metabolism by deacetylation of PGC-1 $\alpha$.

Other studies have shown that SIRT1 deacetylates transcription factors that are involved in the mammalian cellular stress response. Findings reported by Brunet et al., (2004), provided evidence that SIRT1 interacted with members of the stress-response FOXO transcription factor family known as Forkhead. Specifically, it was found that SIRT1 and the transcription factor FOXO3 formed a complex when cells were exposed to oxidative stress. When this occurred, SIRT1 deacetylated FOXO3 and increased FOXO3's ability to induce cell cycle arrest (Figure 6). This also inhibited FOXO3's ability to induce cell death. This implies that "one way in which members of the SIR-2 family of proteins may increase organismal longevity is by tipping FOXO-dependent 
responses away from apoptosis and toward stress resistance" (Brunet et al., 2004). Another intriguing finding was that SIRT1 physically binds to a component of NF-KB and inhibits its effects on gene expression (Yeung et al., 2004). Therefore, perhaps at least one member of the Sirtuin family may enhance longevity by decreasing the inflamm-aging process via NF-KB. These findings suggest that the elevation of SIRT1 levels associated with caloric restriction may impart some of its increased longevity effects by decreasing the effects of NF-KB.

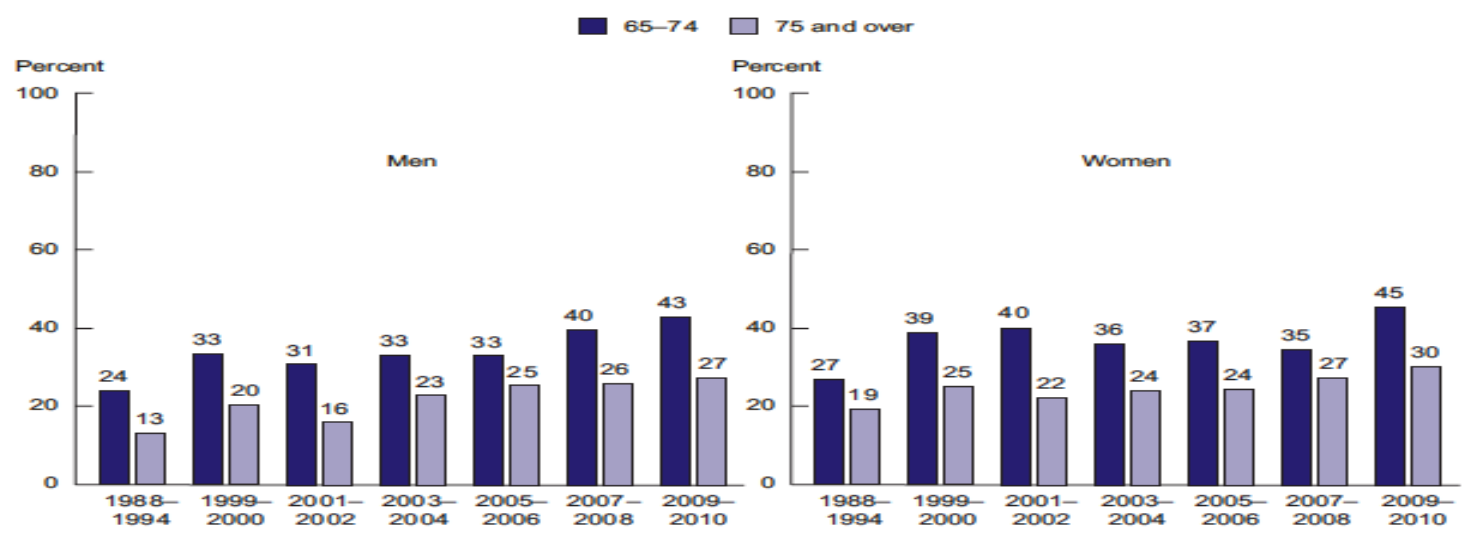

Figure 6: SIRT1 binds and deacetylates FOXO3 to affect cell cycle arrest.

In addition, recent work has also shown beneficial effects of dietary components such as quercetin (a natural polyphenolic flavonoid) and resveratrol (a polyphenol found in relatively high amounts in grapes) may be via activation of SIRT1 (Davis et al., 2009; Knutson and Leeuwenburgh, 2008). SIRT1 has also been reported to modulate plasma glucose levels and insulin sensitivity of tissues (Metoyer and Pruitt, 2008). There is now a significant number of studies on how dietary components regulate SIRT1 and other SIRT family members. In fact, the number of studies is too significant to report in this 
review of literature. In view of the findings related to the multiple roles of SIRT1 in regulating so many vital processes including lifespan, it seems likely the investigation of ways to manipulate SIRT activity via dietary and lifestyle options will expand dramatically in the near future.

\section{Characterization of the Sirtuins}

Research is underway to characterize other Sirtuin family members and as a result it has been shown that SIRTs 1,2,6, and 7 reside mostly in the nucleus but 3,4, and 5 are in the mitochondria most of the time. SIRT3 is especially intriguing because it has been shown to shuttle from the cytosol to the mitochondria during cellular stress (Scher et al., 2007). This protein appears to have effects on multiple cellular components including genes in the nucleus and the mitochondria although most of its effects appear to be in mitochondria. For example, a recent study by Ahn et al., (2008) indicated SIRT3 upregulates ATP production by enhancing levels of electron transport chain Complex I components. In addition, it was recently shown that SIRT3 levels significantly decreased with age and this was associated with decreased ATP production (Lanza et al., 2008).

Protein acetylation in the mitochondria is now believed to be a significant part of regulation of mitochondrial processes (Zhao et al., 2010). A recent study reported acetylated sites on 195 proteins including a significant number of non-histone proteins. It is of interest that 133 of the proteins were mitochondrial proteins (Kim et al., 2006). SIRT3 appears to be the major regulator of mitochondrial acetylation and this is supported by experiments that showed no significant differences in mitochondrial 
acetylation were found in mice lacking SIRT4 and 5 (Lombard et al., 2007) while hyperacetylation was observed in SIRT3 null mice. Low SIRT3 is also implicated as having a role in the hyperacetylation of mitochondrial protein that occurs in mice with a fatty liver due to a chronic high fat diet (Kendrick et al., 2011). In the livers of mice fed a high-fat diet there was a decrease in SIRT3 activity, a 3-fold decrease in NAD+ levels and increased oxidation of mitochondrial proteins. This was associated with reduced activity of electron transport chain Complexes III and IV and this could increase the risk of hepatic lipotoxicity (Kendrick et al., 2011) (Figure 7). Therefore it appears that SIRT3 is a key regulator of mitochondrial metabolism and is sensitive to dietary effectors such as a high fat diet.

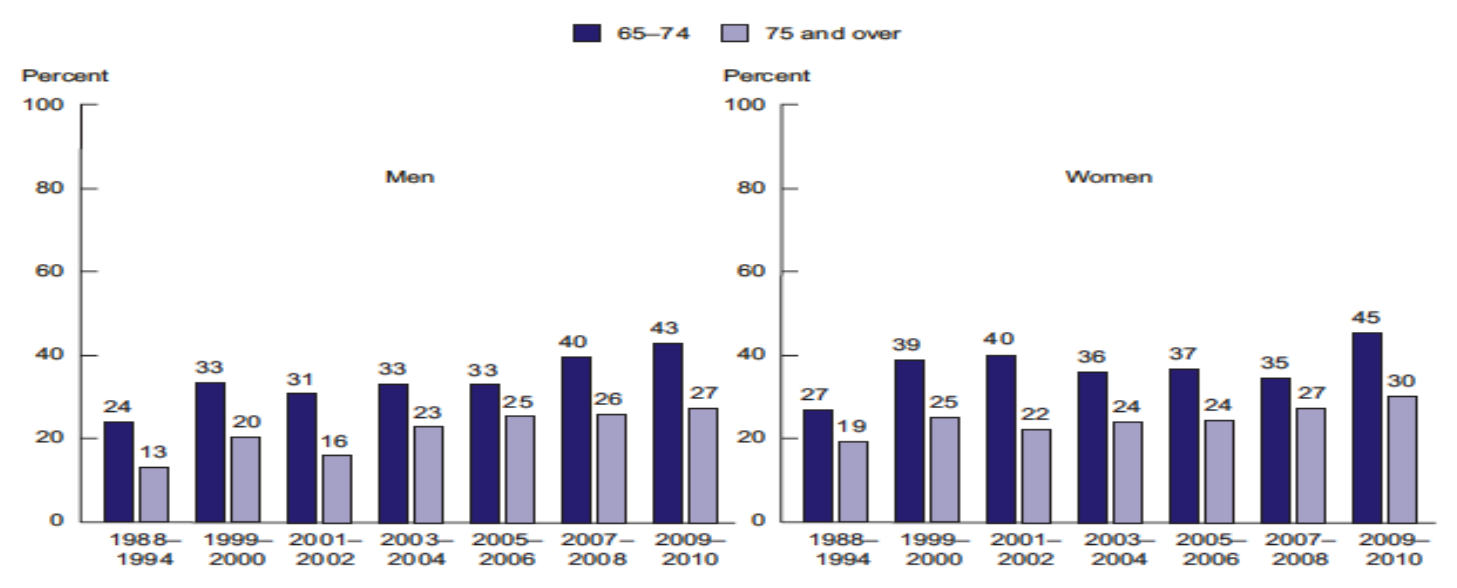

Figure 7: Effects of a high fat diet on SIRT3 and associated factors in mice.

Although the mechanisms remain largely unexplained, evidence suggests that some of the beneficial effects of $\mathrm{CR}$ on longevity involve alterations in mitochondrial functions (Anderson et al., 2008). Studies have shown that CR tends to increase 
mitochondrial biogenesis and decrease reactive oxygen species (ROS) in mammals and these responses tend to decrease oxidative damage to macromolecules and cellular damage, two items that are associated with reduced longevity (Figure 8). Because of the vital role acetylation plays in mitochondrial function it stands to reason that acetylation is involved in CR and that SIRT3 must play a role. Indeed, it has been shown that SIRT3 increases mitochondrial biogenesis via activation of the transcription factor known as PGC-1 $\alpha$ (Palacios et al., 2009; Pillai et al., 2010; Shi et al., 2005). The reciprocal is also true as PGC-1 $\alpha$ stimulates SIRT3 expression by binding to the SIRT3 promoter (Kong et al., 2010) (Figure 8). PGC-1 $\alpha$ is a co-activator protein that is responsible for affecting the expression of a large number of genes, in fact so many that it is referred to as a master regulator of gene expression and metabolism. Given the apparent connection between SIRT3 and PGC-1 $\alpha$ there seems no doubt that SIRT3 has the ability to regulate a high number of cellular processes to affect the status and longevity of organisms.

Less is known about the roles of SIRTs 4 and 5 as compared to SIRTs 1 and 3. SIRT4 is present in the mitochondrial matrix and is highly expressed in kidney, heart, brain, liver, and pancreatic beta-cells (Ahuja et al., 2007; Haigis et al., 2006). During CR SIRT4 expression declines in the liver but its levels increase in genetic models used to mimic diabetes (Haigis et al., 2006; Nasrin et al., 2010). Interestingly, to this point no deacetylase activity has been found for SIRT4 (Aluja et al., 2007; Haigis et al., 2006). However, it has been shown in mice that SIRT4 uses ADP to ribosylate glutamate dehydrogenase (GDH) resulting in inactivation of the enzyme (Haigis et al., 2006). GDH converts glutamate to $\alpha$-ketoglutarate and repression of GDH by SIRT4 decreases the 


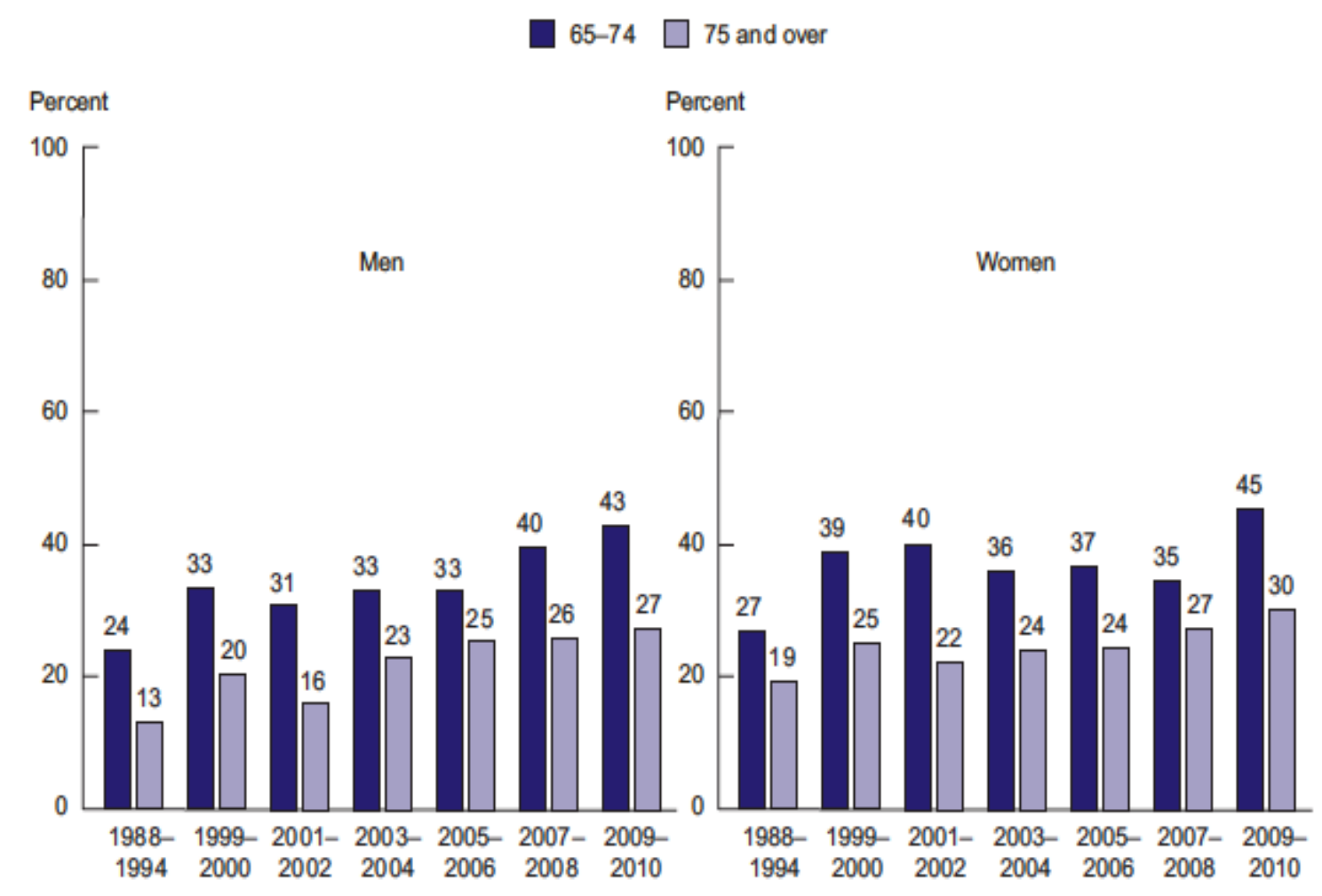

Figure 8: The effects of caloric restriction on SIRT3 activity, mitochondrial biogenesis, and longevity.

amino acid stimulation of insulin secretion from pancreatic beta-cells (Haigis et al., 2006) (Figure 9). Therefore, reduced SIRT4 activity allows higher GDH activity and amino acid-stimulated insulin secretion during CR when amino acids are being used as an energy source at a higher level. Another recent study has also shown that SIRT4 knockdown in tissue culture and mouse liver cells caused increased expression of fatty acid metabolism enzymes (Nasrin et al., 2010). Whether or not SIRT4 will be found to have deacetylase activity remains to be determined. However, it is already apparent that SIRT4 plays a role in regulating energy pathways. 


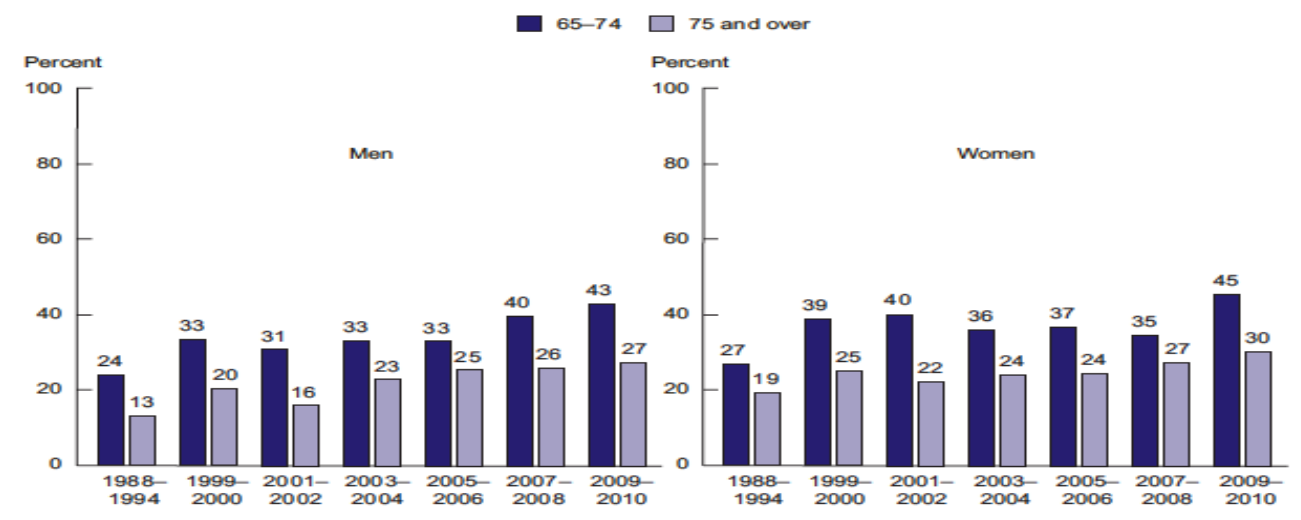

Figure 9: SIRT4 inactivates glutamate dehydrogenase (GDH) by ribosylation. The result tends to be decreased insulin stimulation.

SIRT5 appears to differ from SIRTs 3 and 4 in that its liver levels do not seem to change in response to CR (Nakagawa et al., 2009; Schwer et al., 2009). SIRT5 null mice do not show any major phenotype and there is not a difference in mitochondrial acetylation of proteins (Lombard et al., 2007) indicating a distinction from SIRT3 null mice. SIRT5 does not appear to have robust deacetylase activity with respect to histone proteins (Black et al., 2008; Schlicker et al., 2008). However, it has been shown that SIRT5 interacts with and deacetylates carbamoyl phosphate synthetase 1 (CPS1) and this activates the enzyme (Nakagawa et al., 2009) (Figure 10). CPS1 combines ammonia with carbon dioxide in the first, rate-limiting step of the urea cycle in the mitochondria of liver cells. The study by Nakagawa et al., (2009) showed that SIRT5-deficient mice had elevated levels of ammonia during a prolonged fast due to insufficient up-regulation of CPS1 activity. Therefore, SIRT5 appears to play a key role in the regulation of the urea cycle and ammonia disposal. To date, this is the only known role for SIRT5 but it seems likely that additional functions will be uncovered. 


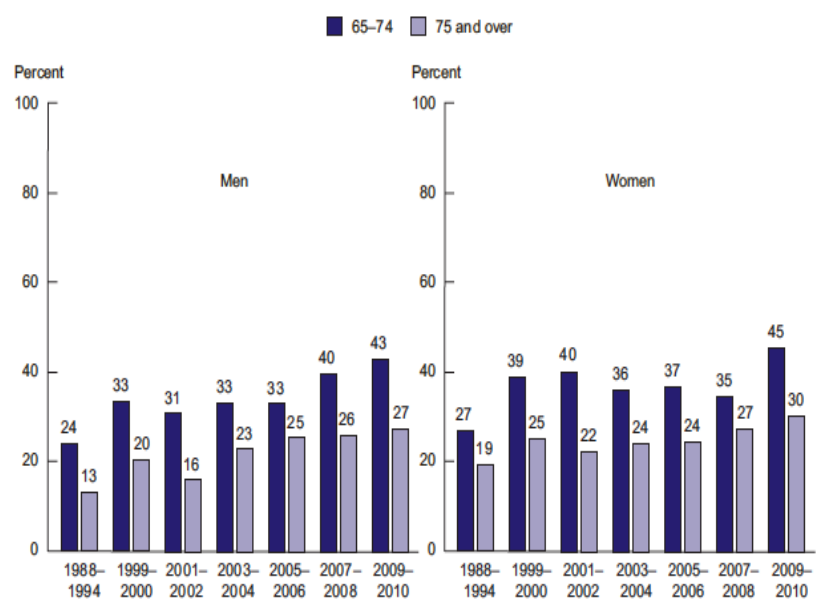

Figure 10: SIRT5 activates carbamoyl phosphate synthetase 1 (CPS1) by deacetylation.

\section{Defining a Role for SIRT6}

SIRT6 is one of the well-characterized members of the SIRTs family and it has been described as having a role in numerous functions. A few years ago, Michishita et al., (2008) provided evidence that SIRT6 binds to telomere chromatin and can modify its structure by functioning as a NAD-dependent deacetylase. Their work indicated SIRT6 could remove an acetyl group from histone H3 lysine 9 (H3K9) and that this can modify the structure of the telomeric chromatin. Telomeres are long repeating sequences of DNA that exist on the ends of each of the chromosomes (McClintock, 1941; Artandi, 2006). Maintenance of telomere structure has been shown to be vital in protecting against genomic instability and that telomere dysfunction can lead to tumor formation (Gisselsson et al., 2001; Meeker et al., 2004). Michishita et al., (2008) utilized knockdown experiments and provided evidence that loss of SIRT6 function results in complications similar to Werner Syndrome (Multani et al., 2007). Additional work by 
this research group showed that SIRT6 is also involved in H3K56 deacetylation and that this is important for the regulation of cell cycle arrest (Michishita et al., 2009). Therefore, the last few years have suggested that SIRT6 has an important role in protecting cellular telomere structure thereby maintaining proper regulation of the cell cycle and potentially protecting against cancer. Consequently SIRT6 may be important for protection against cancer since dysfunction of telomere structure and cell cycle regulation may lead to cancer.

Another theory related to tumorigenesis is that cells must accumulate several DNA mutations as they change from normal cells to cancer cells. Because cells have several DNA repair mechanisms/pathways there is typically an inherent ability to repair DNA before mutations cause cellular transformation to cancerous cells. One of the first studies to link SIRT6 to the DNA repair systems was one using SIRT6 deficient mouse embryonic fibroblasts (MEFs) and stem cells (Mostoslavsky et al., 2006). It was reported that SIRT6 deficient cells were more sensitive to DNA damaging agents and they divided more slowly than wildtype cells. The data also indicated that SIRT6 was involved in regulating base excision repair (BER), one of the DNA repair pathways (Mostoslavsky et al., 2006). However, at this point the precise role of SIRT6 in BER is yet to be defined.

Another DNA maintenance mechanism is the repair of double-strand breaks (DSB) in the DNA structure. When DNA contains a mutation that is more significant than a single nucleotide mismatch then a DSB is a typical result. The DSB can then lead to chromosomal end fusion and genomic instability. In 2009, McCord et al. showed that SIRT6 participates in DSB DNA repair by forming a macromolecular complex with the DNA DSB repair protein DNA-dependent protein kinase. The interaction with SIRT6 
stabilizes the kinase attachment to chromatin and facilitates DSB repair (McCord et al., 2009). In 2011 it was reported that oxidative stress leading to DSB causes SIRT6 to translocate to the site of the DNA DSB (Mao et al., 2011). These studies suggest an important role for SIRT6 in genomic stability because SIRT6 appears to support DSB repair. SIRT6 was found to associate with Poly-ADP-ribose Polymerase 1 (PARP1) during the conditions of oxidative stress. PARP1 is an enzyme that modifies nuclear proteins by ADP-ribosylation and is involved in a number of processes including DNA repair. The result of SIRT6-PARP1 association was ribosylation of lysine residue 521 of PARP1 and its activation which enhanced DSB repair during the oxidative stress conditions (Mao et al., 2011). In summary, it appears SIRT6 is important for DNA repair by both the BER and DSB pathways.

\section{SIRT6-Deficient Phenotype}

SIRT6 deficiency appears to have more detrimental effects as compared to deficiencies of the other SIRT family members. Work by Mostoslavsky et al., (2006) described the phenotype of SIRT6 knockout mice as one that leads to numerous abnormalities early in the life cycle. The mice are born with an apparently normal phenotype but it digresses rapidly and at about three weeks of age they develop severe conditions that lead to death at about four weeks of age. Metabolic defects are significant and include low levels of serum IGF-1 and acute onset of hypoglycemia. The SIRT6deficient mice also exhibit total loss of subcutaneous fat, osteopenia and lymphopenia among documented conditions (Mostoslavsky et al., 2006). Based on the phenotype of 
SIRT6 knockout mice it is obvious that SIRT6 plays a crucial role in vital processes although the precise relationship between SIRT6 function and each of the observed complications is not known.

Recent work using the SIRT6 knockout model has provided important information in defining the role of SIRT6 in glucose homeostasis and how it may relate to lifespan (Zhong et al., 2010). SIRT6 deficiency results in lethal hypoglycemia at approximately four weeks of age. The hypoglycemia occurs in the context of increased glucose uptake into brown adipose tissue and muscle tissue. Blood insulin levels were low and hepatic gluconeogenesis was elevated suggesting that the pancreas and liver were responding to low blood glucose rather than causing it (Zhong et al., 2010). Additional experiments showed that SIRT6 deficiency caused elevated mRNA and protein levels of the membrane glucose transporter GLUT1. Moreover, the expression levels of five key glycolytic genes were increased (Zhong et al., 2010). Chromatin immunoprecipitation (ChIP) assays indicated that SIRT6 bound to the promoter regions of the five glycolytic genes and that SIRT6 deficiency increased histone H3K9 acetylation of the promoters of these genes (Zhong et al., 2010). Because the hypoxiainducible transcription factor Hifl $\alpha$ is an important regulator of enhanced glucose utilization under certain conditions (Lum et al., 2007; Seagroves et al., 2001), investigators have focused on it to determine if there was an interaction between Hifl $\alpha$ and SIRT6. Co-immunoprecipitation assays provided evidence that there was an interaction between the two proteins and that SIRT6 normally represses the activity of Hifl $\alpha$ (Zhong et al., 2010). Further experimentation revealed that SIRT6 relies upon its interaction with Hifl $\alpha$ in an important regulatory mechanism to control glucose 
metabolism (Zhong et al., 2010). These findings indicate that SIRT6 functions as a H3K9 deacetylase to decrease glucose metabolism.

\section{$\underline{\text { SIRT6 Over-expression and Effects on Metabolism and Lifespan }}$}

Researchers recently found that male transgenic mice overexpressing SIRT6 had a significantly longer lifespan than wild-type (WT) mice (Kanfi et al., 2012). Interestingly, there was not enhanced lifespan in the female transgenic mice of the same study. Researchers used two transgenic mouse lines made from two different founders to substantiate that findings were not due to a genetic aberration from the transgenic method. The enhanced lifespan in male mice was present in both transgenic lines. The mean lifespan of SIRT6-transgenic relative to WT mice was increased by $14.8 \%$ and $16.9 \%$ in the two SIRT6 transgenic lines compared to WT. The reason for the longer lifespan in SIRT6 enhanced mice was not easily explained although the authors reported intriguing data and potential mechanisms (Kanfi et al., 2012). Research has indicated that SIRT6 plays a crucial role in maintaining genetic stability (Mostoslavsky et al., 2006) and because malignant tumors are a common cause of death in mice it is important to investigate tumor numbers in mice overexpressing SIRT6. Examinations by Kanfi et al., (2012) showed no significant differences between WT and transgenic mice in the tumor spectrum or incidence.

The study by Kanfi et al. also found differences in metabolic signaling including that SIRT6 overexpression had a positive effect on blood glucose regulation but this effect was not sex-specific (Kanfi et al., 2012). Further analysis revealed significant 
differences in metabolic signaling molecules and pathways between WT and SIRT6 transgenic mice. IGF1 levels were significantly different between male WT and transgenic mice but not between female mice and these differences coincided with differences in expression levels of IGFBP1 (Kanfi et al., 2012), the molecule believed to be the main acute effector of IGF1 levels (Lee et al., 1997). Kanfi et al. also examined IGF1 signaling in some tissues and found that the levels of phosphorylated AKT, FOXO1, FOXO3, and IGF receptor were significantly lower in the white adipose tissue of male but not female SIRT6 transgenic mice. These differences in IGF1-related molecules are especially intriguing given the relevance of IGF1 in the aging process (Kenyon, 2010; Holzenberger et al., 2003). Although these findings do not explain the precise role of SIRT6 in aging it does suggest specific aspects that need to be further examined.

The current epidemic of obesity and metabolic syndrome compels investigations into whether anti-aging factors such as SIRT6 may be protective even in the context of obesity. To explore these interrelationships, a recent study examined the effects of SIRT6 overexpression in mice in the context of diet-induced obesity (Kanfi et al., 2012). WT and SIRT6 transgenic mice were fed a high-fat diet (HFD) for 16 weeks that contained $60 \%$ of calories from fat. In addition, separate groups of WT and SIRT6 transgenic mice that consumed standard chow served as controls. No significant differences between any of the four groups were found for food intake or body weight. However, when fed with HFD the SIRT6 transgenic mice had significantly lower total body fat and higher lean body mass than their WT littermates (Kanfi et al., 2012). When fed HFD, SIRT6 transgenic mice also had lower serum triglycerides (33\% lower), lower 
LDL-cholesterol (30\% lower) and improved glucose uptake during glucose tolerance testing. Transcription profile analysis indicated that the SIRT6 transgenic mice had lower levels of angiopoietin-like protein 4 (ANGPTL4) and Diglyceride Acyl Transferase 1 (DGAT1) as compared to their WT littermates (Kanfi et al., 2012). ANGPTL4 negatively regulates lipoprotein lipase (Yoshida et al., 2002), the enzyme that hydrolyzes triglycerides from plasma lipoproteins so a decrease in ANGPTL4 activity caused by elevated SIRT6 could be a mechanism that causes a decrease in plasma triglycerides. DGAT1 is an intracellular enzyme that is involved in triglyceride synthesis (Cases et al., 1998 ) and the $50 \%$ decrease in DGAT1 expression in fat tissue of SIRT6 transgenic mice would be expected to significantly decrease triglyceride synthesis (Kanfi et al., 2012). Researchers were also able to determine that SIRT6 directly binds to the DGAT1 promoter and that there was a 3.5-fold higher level of SIRT6 bound in the transgenic mice as compared to their WT littermates (Kanfi et al., 2012). These data suggest SIRT6 is an important repressor of DGAT1 expression. Overall, results from the work of Kanfi et al., (2012) demonstrate SIRT6 overexpression is protective against HFD-induced damage such as lipotoxicity, increased body fat storage and aberrations in regulation of glucose homeostasis.

\section{$\underline{\text { SIRT6 and NF-KB }}$}

The family of transcription factors known as NF-KB has also been implicated in the aging process (Salminen et al., 2008). One of the key components of NF-kB is the factor known as RELA or p65 because it has been shown to affect the regulation of a 
variety of genes ( $\mathrm{Li}$ et al., 2008). A recent study provided evidence of a direct relationship between NF-KB and SIRT6 when it was shown that RELA interacts physically with SIRT6 thereby suggesting that these factors cooperate in regulating certain processes (Kawahara et al., 2009). Researchers used immunoprecipitates (IPs) from 293 T cells expressing FLAG-tagged SIRT6 and Western blot analyses to show SIRT6 binds RELA and it appears specific to SIRT6 as compared to other SIRT members. When IPs were done using endogenous proteins it was also shown that RELA binds to SIRT6 preferentially over other SIRTs (Kawahara et al., 2009). Chromatin immunoprecipitation (ChIP) analysis indicated TNF- $\alpha$ enhanced levels of SIRT6 bound to promoters of RELA target genes and that this resulted from RELA recruiting SIRT6 to the promoters of genes affected by RELA (Kawahara et al., 2009). Subsequent experiments provided evidence that SIRT6 directly inhibits expression of certain NF-KB target genes and that the mechanism appears to be via SIRT6-directed deacetylation of histone H3 lysine 9 residues that destabilizes RELA binding to chromatin (Kawahara et al., 2009). To substantiate these findings, it was also shown that SIRT6 depletion led to increased expression of NF-KB target genes and RELA deficiency via heterozygosity improved the phenotype of SIRT6 deficient mice (Kawahara et al., 2009). Taken together, these findings point out a direct interaction of SIRT6 and NF-KB that has significant health implications. Although the precise role of this interaction remains to be fully defined (Natoli, 2009), its potential importance to health and well-being makes it worthy of future research efforts.

Recent work has also focused on the relationship of SIRT6 and NF-KB and their genome-wide effects on gene expression. A recent study utilized genome-scale ChIP- 
chip assays with oligonucleotide arrays to characterize the binding of SIRT6 and RELA in mouse embryonic fibroblasts (Kawahara et al., 2011). The assays were done before and after stimulation with TNF- $\alpha$ to examine effects of the stress response of these two protein factors. Results indicated that altogether SIRT6 can bind up to approximately 5050 gene promoters including 1899 genes in unstimulated cells. Upon TNF- $\alpha$ stimulation there was a significant and dynamic movement of SIRT6 from some promoters to others within minutes following TNF- $\alpha$ addition (Kawahara et al., 2011). Analyses also showed that RELA bound to 2738 promoters. Assays revealed that on 1481 promoters both SIRT6 and RELA bound and that RELA plays a significant role in SIRT6 localizing to certain gene promoters (Kawahara et al., 2011). These findings provided more evidence of the cooperation of these two factors in regulating numerous genes in controlling cellular responses.

\section{$\underline{\mathrm{NF}-\mathrm{KB}}$}

One of the popular theories of the aging process is known as the inflamm-aging theory of aging (Troen, 2003). According to this theory, it is the systemic inflammation that results from enhanced oxidative stress during aging that causes the response of signaling pathways and effector molecules that promote tissue breakdown. One of the key sensing and signaling molecules involved in this process is known as NF-KB (Salminen et al., 2008). This molecule functions as a transcription factor that regulates the expression of numerous genes including those that can cause the breakdown of 
skeletal muscle during aging, obesity, and/or insulin resistance. Because of its crucial role in aging, the characteristics of NF-KB will be discussed in greater detail below.

$\mathrm{NF}-\mathrm{KB}$ is a transcription factor that has been determined to be a key signaling molecule in vertebrates because it reacts to a large number of stimuli, including oxidative stress, and is able to elicit a multitude of cellular responses including cellular life or death (Figure 11). Previous work has suggested that NF-KB is involved in activating proteolysis leading to skeletal muscle loss in cachexia, sarcopenia, disuse atrophy, and aging.

$\mathrm{NF}-\mathrm{KB}$ is a well-characterized transcription factor that is expressed ubiquitously and is required for several critical processes including inflammation, infection, and oxidative stress (Salminen et al., 2008). NF-кB is composed of a number of proteins (RelA/p65, cRel, RelB, p50, and p52), known as NF-KB family members that cooperate to form a complex. However, in most tissues p65/p50 heterodimers are most common and considered to be the "classic" active form of NF-KB. NF-kB can be maintained in an inactive state in the cytosol through the binding of an inhibitor of $\mathrm{kB}$ (ІкB). There are three isoforms of ІкB (ІкB $\alpha$, ІкB $\beta$, ІкB $\varepsilon$ ) with each form possessing the ability to inhibit NF-кB. Upon certain stimuli, ІкB is phosphorylated by IкB Kinase (IKK) in a step that targets IкB for ubiquitination and subsequent proteolysis thereby leaving NF-кB unbound (Li et al., 2008). This process allows the unbound NF-KB to translocate to the nucleus where it can affect gene expression through binding NF-KB-target sequences located in the promoter region of specific genes (Figure 12). One of the hallmark features of NF-KB activation is an increased rate of proteolysis via the intracellular ubiquitin-proteasome pathway. NF-кB enhances the activity of several ligases involved in the ubiquitination 
step and proteasome activity to increase protein breakdown (Cai et al., 2004). Recently, studies have focused on how NF-kB may trigger skeletal muscle breakdown during disease states such as cachexia and disuse. In addition, several recent studies have attempted to determine whether or not NF-KB may be a key regulator of skeletal muscle loss during aging however the mechanism remains unclear.

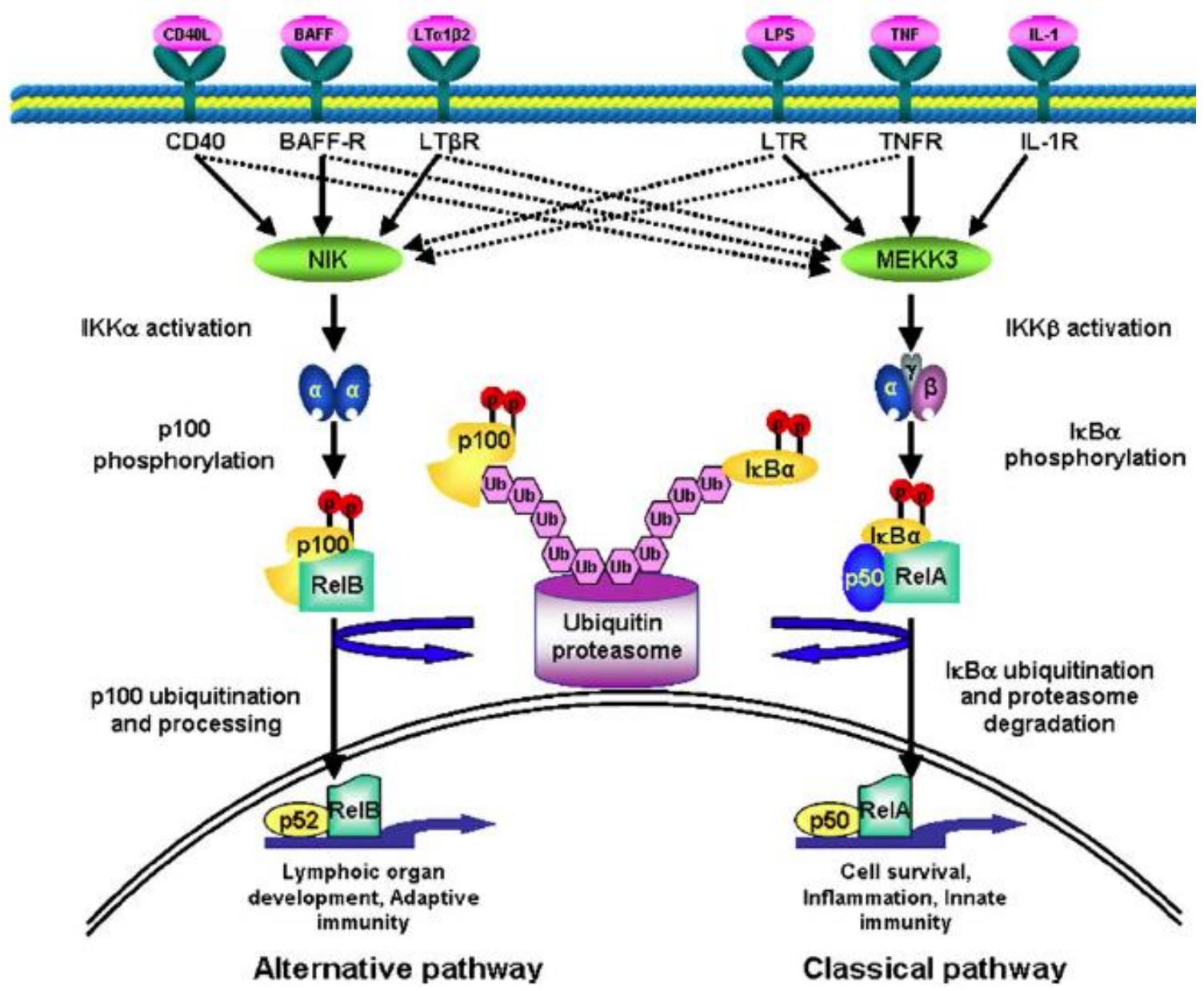

Figure 11: NF-кB signaling pathways. The diagram represents a simplified version of the two NF-кB signaling pathways known as the "classical" and "alternative" pathways. (From Li et al., 2008) 


\section{Proteolysis Pathways}

Muscle loss occurs in adults for a variety of reasons such as disease, disuse and sarcopenia. Significant loss of skeletal muscle can have devastating effects including but not limited to reduced metabolic rate, reduced insulin sensitivity, reduced strength, increased prevalence of falls and inability to live and function independently. Old age can result in a $20-30 \%$ decline in muscle mass over time and yet many of the cellular mechanisms responsible remain undetermined.

Several cellular proteolytic systems exist but the four most prominent include the lysosomal system, the calcium-dependent system, the caspase-dependent processes and the ubiquitin-proteasome system. Each system has different components and functions differently in the degradation of proteins. The caspases belong to the family of cysteine proteases and have a prominent role in the apoptosis process under certain conditions. Although apoptosis and the caspases are crucial during certain events or conditions it is not yet clear how relevant caspases are in the regulation of muscle mass (Du et al., 2004; Moresi et al., 2008). The calcium-dependent system also is composed of several cysteine proteases known as Calpains and at least one inhibitor called calpastatin. Calpains tend to only hydrolyze a minimal amount of peptide bonds on their targets as they inactivate the protein or facilitate its degradation by other proteolytic pathways (Costelli et al., 2005; Smith and Dodd, 2007). 


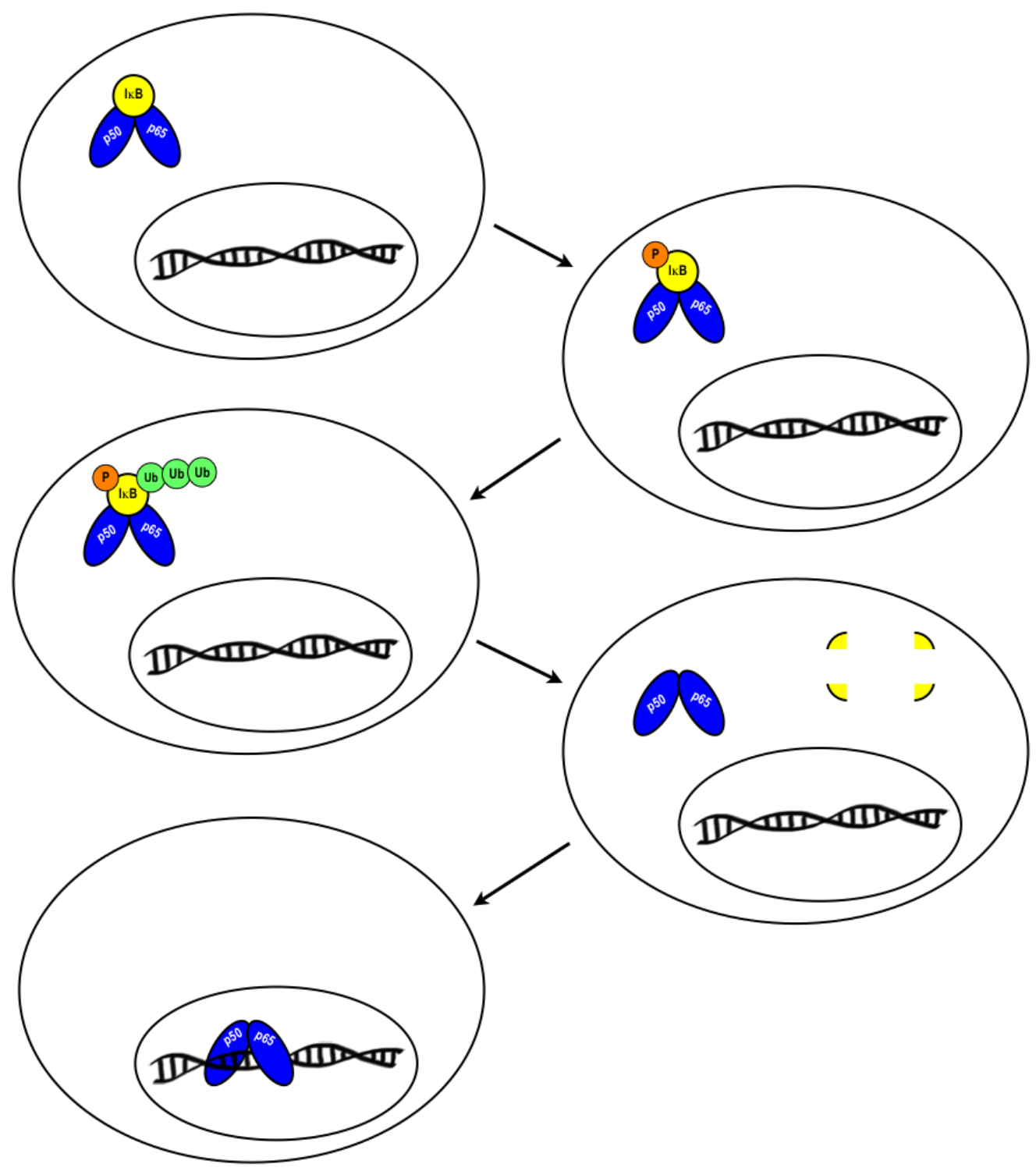

Figure 12: Activation of NF- $\mathrm{KB}$ p65/p50 heterodimer and translocation to $\mathrm{NF}-\mathrm{KB}$ response elements in nucleus.

The lysosomal system seems to be somewhat nonselective and appears to target the longer-lived proteins in cells (Kadowaki and Kanazawa, 2003). The system has been shown to elicit elevated activity following a 6-hr nutrient starvation period so lysosomal autophagic activity seems to be sensitive to nutrient status (Grumati et al., 2010). A class of cysteine proteases known as autophagins have been suggested to be involved in the 
formation of the autophagosomes and these proteins seem to be particularly abundant in skeletal muscle (Marino et al., 2003). In addition, denervation or fasting has been shown to increase expression of autophagy-related genes during muscle atrophy (Mammucari et al., 2007; Ogata et al., 2010; O'Leary and Hood, 2009). To summarize, the lysosomal system appears to have a significant role in muscle proteolysis.

Most evidence indicates that the Ubiquitin-proteosome system (UPS) is the dominant system of proteolysis in muscle cells (Attaix and Taillandier, 1998). Activity of the UPS can be upregulated under numerous conditions including disease (e.g. cancer cachexia), disuse, or stress such as nutrient deprivation. Aging also appears to enhance the activity of the ubiquitin-proteosome pathway and it has been reported that the decrease in proteosome activity that occurs following a meal in young adult rats is not as significant in older rats. In other words, proteolysis occurs at a higher level in older rats than in adult rats following a meal. However, an elevated level of leucine restored the postprandial inhibition of proteolysis in old rats (Combaret et al., 2005). These data suggest the ubq-proteasome pathway is leucine-sensitive and that older animals may require elevated levels of leucine to down-regulate proteolysis. Proteasomes are large multi-subunit complexes found in the nucleus and cytosol that selectively degrade intracellular proteins that have had ubiquitin attached. Ubiquitin is a highly conserved 76amino acid protein that signals proteins to be transported to the multi-enzyme proteolytic complex known as the $26 \mathrm{~S}$ proteasome. The proteosome core is composed of 28 subunits arranged in four heptameric, tightly stacked, rings to form a cylindrical structure. In the ubiquitin-proteosome degradation pathway, Ubq is first covalently ligated to target proteins by a multi-enzymatic system consisting of Ubiquitin-activating (E1), Ubiquitin- 
conjugating (E2), and the Ubiquitin-ligating (E3) enzymes. Poly-ubiquitination of the substrate protein results in the protein being targeted to the proteosome for degradation. Two novel E3 ubiquitin ligases have been identified and described to be specifically expressed only in cardiac and skeletal muscle (Bodine et al., 2001). The ligases were referred to as atrogin-1 (muscle atrophy F-box) and MuRF-1 (muscle ring finger 1). Studies have shown these ubiquitin ligases to be upregulated by TNF $\alpha$, NF- $\mathrm{KB}$ (Cai et al., 2004) and reactive oxygen species (Li et al., 2003). A study by Clavel et al., (2006) indicated that atrogin-1 and MuRF1 were upregulated in age-related proteosomedependent proteolysis in rat tibialis anterior muscle. Moreover, in studies using chickens, leucine was found to decrease myofibrillar proteolysis by down-regulating the ubiquitin-

proteosome pathway (Nakashima et al., 2005). Leucine deprivation was shown to increase components of the ubiquitin-proteosome pathway in mouse $\mathrm{C} 2 \mathrm{C} 12$ cells (Sadiq et al., 2007). Specific details regarding key leucine-dependent signaling molecules remain to be determined.

\section{Leucine Effects}

Typically in adults the amount of muscle tissue present depends upon the balance between muscle protein synthesis (anabolism) and breakdown (degradation or proteolysis). Numerous conditions, hormones, and nutrients play key roles in the balance between anabolism and muscle proteolysis. For example, it has been known for years that leucine, an essential amino acid for humans, is an extremely important signaling molecule in muscle cells. Leucine appears to have a unique role in cellular signaling 
pathways that regulate protein synthesis and protein breakdown. The anti-catabolic effects of leucine were reported over 45 years ago (Hider et al., 1960) and extensive work since then has confirmed the anti-catabolic effect and some of the mechanisms have been defined. Experiments indicated the leucine metabolite $\beta$-hydroxy- $\beta$-methylbutyrate (HMB) is responsible for leucine's ability to decrease protein breakdown (Nissen et al., 1996). Follow up studies have shown leucine and HMB decrease protein degradation by decreasing activity of the ubiquitin-proteasome proteolytic pathway (Combaret et al., 2005; Nakashima et al., 2005; Smith et al., 2005). Evidence indicates sufficient amounts of leucine promote protein synthesis through both insulin-dependent and insulinindependent signaling pathways (Kadowaki and Kanazawa, 2003; Kimball and Jefferson, 2006). Leucine is able to activate cellular signals that initiate protein translation via mammalian target of rapamycin (mTOR) signaling and activation of the protein elongation initiation factor known as eIF4G (Layman and Walker, 2006; Kimball and Jefferson, 2001; Crozier et al., 2005). Leucine's activation of these proteins leads to increased activity of the ribosomal translation complex and elevated protein synthesis levels in cells.

Lack of leucine (or certain other amino acids) within a cell can initiate a pathway known as the amino acid response pathway. This results in activation of the protein GCN-2 (general control nonderepressible) a kinase that phosphorylates the translation elongation factor eIF- $2 \alpha$ that causes a nearly comprehensive decrease in protein synthesis (Kilberg et al., 2009). However, a mammalian protein known as ATF-4 (activating transcription-4) is actually translated at a higher level during those conditions (Kilberg et al., 2009). ATF-4 has been reported to increase the expression of CHOP (C/EBP 
Homology Protein) also known as gadd153 (growth arrest and DNA damage protein 153). One function of CHOP has been defined as activation of the ER (endoplasmic reticulum) stress response which, among other things, may induce oxidative stress within a cell (Kilberg et al., 2009). Cells may respond to oxidative stress by activating stress response molecules such as the transcription factor NF-kB. Details of the NF-кB pathway were provided in a previous section.

Because leucine can decrease protein breakdown and increase protein synthesis, the net increase in cellular protein levels can be significant. Therefore, adequacy of leucine intake is important to help ensure protein synthesis and retention can be positive at the appropriate times and conditions throughout a person's life. Recent studies have suggested that higher levels of leucine may be required in elderly individuals to decrease skeletal muscle breakdown as compared to young individuals (Katsanos et al., 2006) because of leucine's ability to trigger anabolic and anti-proteolytic signaling pathways (Nakashima et al., 2005). Studies have emerged to suggest that a level of protein intake higher than the current recommendations may facilitate muscle retention in the elderly, possibly due to leucine's protective effect on skeletal muscle retention. Given the high prevalence of sarcopenia and importance of leucine in protein metabolism, the amount of protein and leucine intake should consistently and systematically be considered and evaluated as a means to minimize the detrimental effects of sarcopenia.

\section{SUMMARY}


In summary, there is a great deal more that needs to be investigated and understood about the aging process. This is especially relevant given increasing lifespan and numbers of persons that are or will soon reach the elderly category. In order to improve the health and well-being of the elderly it is important to understand the aging process so that effectiveness of the dietary and lifestyle intervention strategies can be evaluated based on specific and well-described processes involved in aging. For example, the fairly recent discovery of the Sirtuin family members has provided important insight into the aging process and appears to be a promising avenue for the future studies. These efforts should include how diet and lifestyle may influence the Sirtuins as a means of extending lifespan and improving quality of health. Another example is the highly-studied transcription factor known as NF-KB because it has been shown to play a key role in so many processes including those involved in aging. Although much is known about NF-kB there are still important aspects that need to be explained especially given recent information that ties NF-KB and specific Sirtuins together in the aging phenotype. The research described below was performed to provide information related to SIRT6 and NF-KB by measuring protein levels of each in various tissues of adult and old rats. We hypothesize that NF-kB (p65) protein levels would be elevated in tissues of the old rats relative to adult rats. We also hypothesize that SIRT6 protein levels would be lower in the tissues of the old rats as compared to the adult rats. Hopefully, this information contributes toward a better understanding of how these proteins are involved in the aging phenotype.

\section{MATERIALS AND METHODS}


In view of the gaps in knowledge related to molecular mechanisms of aging, we pursued an experimental strategy to provide insight into how NF-kB and SIRT6 protein levels differ in adult and old rats. Our goal was to gather information from this study that may be used to guide future experiments and/or nutritional and lifestyle interventions that may affect NF-kB and SIRT6 in a beneficial manner. We hypothesized that NF-kB levels would be higher in tissues of the old rats and that this may be associated with loss of tissue mass. We hypothesized that SIRT6 levels would be lower in some tissues of the old rats and that lower levels of SIRT6 may be associated with higher levels of NF-KB. To examine these questions, two groups of rats of adult and old age were fed the same diet for the same amount of time prior to their sacrifice and tissue excision. Western blot analyses were performed to quantify and compare levels of NF-kB and SIRT6 protein between tissues and age groups. Details of experimental procedures are described below.

\section{$\underline{\text { Animals }}$}

A total of 14 male Sprague Dawley rats were purchased from Harlan (Indianapolis, IN) at ages 6 months and 21 months (n=7/age-group). All animal procedures were approved by the Cal Poly Institutional Animal Care and Use Committee. Based on the typical lifespan of Sprague Dawley rats, the 6-month-old rats were designated Adult and the 21-month-old were designated Old. Rats were housed in individual cages on a 12-hour light cycle in a temperature-controlled room. Upon arrival, rats were provided basic chow diet for three days prior to changing to the experimental diet, (product \# 510018 modified Leucine level, Dyets, Inc., Bethlehem, PA) for ad 
libitum consumption for 10-17 days. Experimental diet was a low-leucine formula that contained all other essential nutrients as shown in Table 1. Rats were fasted for approximately 12 hours then killed by $\mathrm{CO}_{2}$ inhalation. Rat weights and food intake were measured daily.

\section{$\underline{\text { Tissue Preparation }}$}

Excised tissue was cut up in T-PER ( $\sim 0.2 \mathrm{~g}$ per $4 \mathrm{~mL}$ T-PER $)$ was placed into chilled T-PER (Thermo Scientific, Rockford, IL) with protease inhibitor and EDTA (4 mL T-PER + $40 \mathrm{uL}$ HALT protease inhibitor + $40 \mathrm{uL}$ 0.5 M EDTA) (Thermo Scientific). Tissue was homogenized with a chilled polytron while being kept on ice at all times. Homogenate was centrifuged at $10,000 \mathrm{~g}$ for 5 minutes at $4^{\circ} \mathrm{C}$ and supernatant stored at $-80^{\circ} \mathrm{C}$ in aliquots to avoid freeze-thaw cycles.

\section{$\underline{\text { SDS PAGE and Transfer to Nitrocellulose Membrane }}$}

Tissue protein was quantitated using a standard calibration curve (BCA Protein Assay Kit, Thermo Scientific) by combining $5 \mathrm{uL}$ sample and $45 \mathrm{uL}$ T-PER. SDS PAGE was performed using BIO-RAD Mini-Protean II System (Bio-Rad, Richmond, CA) with 4-20\% Precise acrylamide pre-made gels (Thermo Scientific) run with a HEPES buffering system. Fifty ug of protein was loaded per each well and then SDS-PAGE and Western blotting was performed. A sample from Jurkat cell nuclear extract (Santa Cruz Biotechnology, Santa Cruz, CA) was also loaded on each gel and used as a positive control to locate and quantify the NF-кB p65 and SIRT6 bands. Each well was loaded 
Table 1. Diet Composition

\begin{tabular}{|c|c|}
\hline Ingredient & Grams / Kg pellet \\
\hline L-Arginine (free base) & 4.400 \\
\hline L-Histidine (free base) & 3.200 \\
\hline L-Lysine $\mathrm{HCl}$ & 11.300 \\
\hline L-Tyrosine & 6.400 \\
\hline L-Tryptophan & 1.500 \\
\hline L-Phenylalanine & 6.100 \\
\hline L-Methionine & 3.200 \\
\hline L-Cystine & 2.400 \\
\hline L-Threonine & 4.600 \\
\hline L-Leucine & 1.800 \\
\hline L-Isoleucine & 5.900 \\
\hline L-Valine & 6.900 \\
\hline Glycine & 2.200 \\
\hline L-Proline & 14.300 \\
\hline L-Glutamic Acid & 34.200 \\
\hline L-Alanine & 3.200 \\
\hline L-Aspartic Acid & 7.900 \\
\hline L-Serine & 6.600 \\
\hline Cornstarch & 451.192 \\
\hline Dyetrose & 150.000 \\
\hline Sucrose & 130.000 \\
\hline Cellulose (microcrystalline) & 50.000 \\
\hline Soybean Oil & 40.000 \\
\hline TBHQ & 0.008 \\
\hline Salt Mix \# 210053 & 35.000 \\
\hline Sodium Bicarbonate & 5.200 \\
\hline Vitamin Mix \#310025 & 10.000 \\
\hline Choline Bitartrate & 2.500 \\
\hline
\end{tabular}


with 50 ug tissue protein (tissue supernatant, load buffer at $20 \% \mathrm{v} / \mathrm{v}$, and T-PER to a total volume of $37.5 \mathrm{uL}$ ), $10 \mathrm{uL}$ Rainbow molecular weight markers, and $15 \mathrm{uL}$ Jurkat cell nuclear extract as a positive control for p65 (5 uL Jurkat, $10 \mathrm{uL}$ load buffer, $35 \mathrm{uL}$ TPER). All samples were boiled for four minutes prior to loading. Gels were run at $100 \mathrm{~V}$ for 5 minutes followed by $80 \mathrm{~V}$ for 70 minutes. After electrophoresis, gels and nitrocellulose membranes were soaked in methanol-containing transfer buffer (BupH Tris-Glycine Buffer; Pierce, Thermo Scientific) for 15 minutes. Filter paper was soaked in transfer buffer for approximately 30 seconds, until fully absorbed. A semi-dry gel, membrane, filter paper sandwich was created carefully to assure uniform contact between layers. The Semi-dry Trans-blot system (Bio-Rad) was run at $15 \mathrm{~V}$ for 45 minutes. Membranes were then dried overnight at room temperature.

\section{Western Blotting}

Membranes were washed on a rocking platform three times $(20 \mathrm{~mL})$ for 5 minutes in 1x TBS with $0.5 \%$ Tween-20. Blocking (TBS Starting Block with $0.5 \%$ Tween-20; Thermo Scientific) was performed for 20 minutes $(20 \mathrm{~mL})$, followed by two additional washes. Anti-p65 NF-кB antibodies (Santa Cruz Biotechnology) or anti-SIRT6 antibodies (Sigma, St. Louis, MO) were applied for 90 minutes diluted in $15 \mathrm{~mL}$

Blocking solution (Thermo Scientific). Dilutions were 1:400 for anti-p65 NF-KB and 1:750 for anti-SIRT6. Membranes were washed five times and then secondary antibodies (ImmunoPure Goat Anti-Rabbit IgG $(\mathrm{H}+\mathrm{L})$ Peroxidase Conjugated (Thermo Scientific)) were applied for 60 minutes. Membranes were washed an additional five times. Membranes were then exposed to ECL reagents (SuperSignal West Dura Extended 
Duration Substrate) for 5 minutes (Pierce, Thermo Scientific) prior to visualization and quantitation of bands on a Chemi Doc System (Bio-Rad) using Quantity One software (Bio-Rad). Various amounts of rat tissue and jurkat protein were analyzed by Western blots for p65-NF-KB and SIRT6 to first establish linearity and specificity of the procedures. Subsequently, appropriate amounts of protein were used for Western blot analyses. The Jurkat cell nuclear extract was used to quantify relative amounts of p65 and SIRT6 in samples by expressing band density values after ECL per the Jurkat value on each membrane. A flowchart of the experimental design has been provided below as Figure 13. 


\section{Adult Rats (age 6 months)}

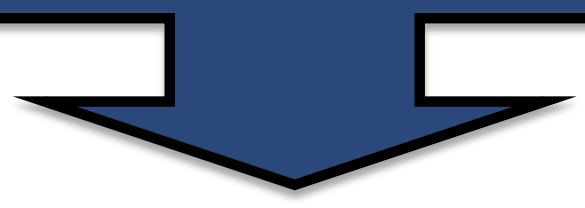

Rats were fed a commercially-prepared
Rats were housed individually and diet

Rats were killed by $\mathrm{CO}_{2}$ inhalation a immediately frozen in liquid nitr

Tissue total cellular protein was prepared in chilled T-PER (Thermo S HALT protease inhibitors Supernatant was obtained b protein was quantitated by BCA Ass 


\section{Figure 13: Flowchart of experimental design.}

RESULTS

\section{$\underline{\text { Body and Tissue Weights }}$}

Rats in the Old age group had a significantly higher body weight than the Adult rats (Table 2). Table 2 shows the average daily intake per group over the entire time period from the time the low-leucine diet started to the time of sacrifice. Although there was a significant difference in body weight, there was not a significant difference in daily food intake between the two groups when the data were expressed as grams of food per day (Table 2). However, when food intake data were expressed relative to body weight the differences were significant and indicated the Old rats consumed less food per day per body weight (Table 2).

Table 2. Average Body Weight \& Food Intake of Adult and Old Rats

\begin{tabular}{lccc}
\hline & Adult ${ }^{1}$ & Old $^{2}$ & $\begin{array}{c}\text { p-value } \\
(2 \text { tailed })\end{array}$ \\
\hline Final Body Weight $(\mathrm{g})$ & $410.43 \pm 23.40$ & $526.29 \pm 39.69$ & 0.0002 \\
Daily Food Intake $(\mathrm{g})$ & $10.19 \pm 1.54$ & $9.89 \pm 0.95$ & 0.6982 \\
Daily Food Intake $(\mathrm{g})$ as \% Body Weight & $2.4 \pm 0.40$ & $1.45 \pm 0.29$ & 0.0014 \\
\hline${ }^{1}$ Values represent means \pm SD from 7 rats aged 6 months & & \\
${ }^{2}$ Values represent means \pm SD from 7 rats aged 21 months & &
\end{tabular}

Numerous tissues were removed and weighed after the rats were killed to examine the effects of age on tissue size. The weights of the tissues are shown in Table 3. Pieces of liver and quadriceps were used for tissue analyses but because these were not excised in their entirety the weights were not recorded. There was a significant difference in 
gross average tissue weights in tibialis anterior, heart, kidney, and lungs (Table 3). However, tissue and muscle weights were also expressed relative to overall body weight (Table 4). Weights of excised Soleus and Gastrocnemius muscles were significantly different in Old vs. Adult rats when values were expressed per body weight (Table 4).

Table 3. Gross Average Tissue Weights (grams)

\begin{tabular}{|c|c|c|c|}
\hline & Adult ${ }^{1}$ & Old 2 & $\begin{array}{l}\text { p-value } \\
\text { (2 tailed) }\end{array}$ \\
\hline Soleus & $0.330 \pm 0.023$ & $0.372 \pm 0.047$ & 0.0632 \\
\hline Tibialis Anterior & $1.299 \pm 0.266$ & $1.477 \pm 0.192$ & 0.0377 \\
\hline Gastrocnemius $^{3}$ & $2.487 \pm 0.304$ & $2.448 \pm 0.264$ & 0.6435 \\
\hline Heart & $1.469 \pm 0.115$ & $1.844 \pm 0.199$ & 0.0073 \\
\hline Kidney & $2.337 \pm 0.134$ & $3.189 \pm 0.287$ & 0.0003 \\
\hline Lungs & $1.912 \pm 0.199$ & $2.398 \pm 0.341$ & 0.0200 \\
\hline
\end{tabular}

${ }^{1}$ Values represent means \pm SD from 7 rats aged 6 months

${ }^{2}$ Values represent means \pm SD from 7 rats aged 21 months

${ }^{3}$ Represents average weight of only one hindlimb gastrocnemius muscle 
Table 4. Average Tissue Weight Per Body Weight (as percentages)

\begin{tabular}{lccc}
\hline & \multicolumn{1}{c}{ Adult $^{1}$} & Old $^{2}$ & $\begin{array}{c}\text { p-value } \\
(2 \text { tailed })\end{array}$ \\
\hline Soleus & $0.0805 \pm 0.0042$ & $0.0710 \pm 0.0112$ & 0.0471 \\
Tibialis Anterior & $0.3181 \pm 0.0704$ & $0.2817 \pm 0.0417$ & 0.1549 \\
Gastrocnemius $^{3}$ & $0.6067 \pm 0.0655$ & $0.4679 \pm 0.0685$ & 0.0010 \\
Heart & $0.3579 \pm 0.0200$ & $0.3526 \pm 0.0535$ & 0.7980 \\
Kidney & $0.5695 \pm 0.0184$ & $0.6064 \pm 0.0459$ & 0.1006 \\
Lungs & $0.4683 \pm 0.0686$ & $0.4589 \pm 0.0829$ & 0.8182 \\
\hline
\end{tabular}

${ }^{1}$ Values represent means \pm SD from 7 rats aged 6 months

${ }^{2}$ Values represent means \pm SD from 7 rats aged 21 months

${ }^{3}$ Represents average weight of only one hindlimb gastrocnemius muscle

Levels of NF-kB (p65) in Various Tissues

In order to examine the tissue levels and the effect of aging on NF-KB (p65) levels, samples of total protein were prepared from each of the isolated tissues. SDSPAGE and Western blot analysis was then used to quantitate levels of NF-кB (p65) in the Adult and Old rats. Differences of NF-KB (p65) were first compared between tissues in the Adult rats Figure 14A. Results indicated NF-KB (p65) was significantly higher in lung as compared to gastrocnemius, heart, kidney, quadriceps and tibialis anterior (Figure 14A). NF-KB (p65) was significantly higher in the liver than kidney, quadriceps and tibialis anterior in the Adult rats (Figure 14A). In addition, heart levels of NF-kB (p65) were significantly higher than tibialis anterior (Figure 14A). The amount of NF-KB (p65) protein in the soleus muscle was significantly higher than the tibialis anterior muscle (Figure 14A). A maximum number of 7 samples were analyzed but some analyses were performed using 4 samples because of unlikely differences. 
Tissue levels of NF-kB (p65) were also compared in the Old rats (Figure 14B). The amount of NF-KB (p65) protein in the lung was significantly higher than gastrocnemius, heart, kidney, liver, quadriceps, soleus and tibialis anterior (Figure 14B). Levels of NF-kB (p65) in the liver were significantly higher than gastrocnemius, quadriceps and tibialis anterior (Figure 14B). NF-кB (p65) protein in the kidney was significantly higher than that of the tibialis anterior (Figure 14B). Soleus levels of NF-кB (p65) were significantly elevated as compared to tibialis anterior (Figure 14B). The comparison of NF-KB (p65) protein levels between tissues indicated some interesting findings including that levels in the lung were significantly higher than other tissues in both the Adult and Old rats (Figure 14A and 14B). 


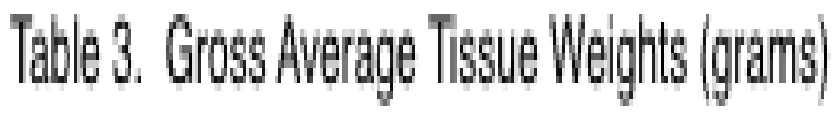

\begin{tabular}{|c|c|c|c|}
\hline & Adulit ${ }^{1}$ & $010^{2}$ & 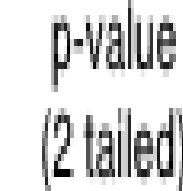 \\
\hline Soleus & $0.330 \pm 0.023$ & $0.372 \pm 0.047$ & 0.0632 \\
\hline Fibialls Anteriflót & $1.299 \pm 0.266$ & $1.477 \pm 0.192$ & 0.0377 \\
\hline Gastrochemilus $^{3}$ & $2.487 \pm 0.304$ & $2.448 \pm 0.264$ & 0.6435 \\
\hline Heart & $1.469 \pm 0.115$ & $1.844 \pm 0.199$ & 0.0073 \\
\hline Kidnèy & $2.337 \pm 0.134$ & $3.189 \pm 0.287$ & 0.0003 \\
\hline Lungs & $1.912 \pm 0.199$ & $2.398 \pm 0.341$ & 0.000 \\
\hline
\end{tabular}


Additional analyses were done to compare NF-KB (p65) protein levels of Adult and Old rats in specific tissues (Figures 15 and 16). Comparisons between age groups revealed that gastrocnemius NF-KB (p65) was significantly higher in the Old rats as compared to the Adult rats (Figure 15A). Quadriceps NF-KB (p65) tended to be higher in the Old rats as compared to the Adult rats (Figure 15B) but the differences did not reach statistical significance $(\mathrm{P}=0.063)$. Levels of NF- $\mathrm{kB}(\mathrm{p} 65)$ in the kidney appeared to be approximately $40 \%$ higher in the Old compared to Adult rats but the values were not statistically significant. These data indicate NF-KB (p65) protein levels are regulated in a tissue-specific and age-dependent manner in rats.

\section{Levels of SIRT6 Protein in Various Tissues}

Duplicate SDS-PAGE gels and transfers were run simultaneously so that NF-KB (p65) could be examined on one nitrocellulose membrane and SIRT6 on the duplicate membrane. SIRT6 protein levels in various tissues were compared in both the Adult and Old rats (Figure 17).

In both the Adult and Old rats, the following statistically significant differences in SIRT6 were observed (Figure 17A and 17B). SIRT6 was significantly higher in quadriceps and kidney as compared to soleus. SIRT6 protein in the quadriceps, gastrocnemius, tibialis anterior and kidney was significantly higher than SIRT6 in the liver. SIRT6 was significantly lower in lung and heart as compared to quadriceps. Gastrocnemius, tibialis anterior and kidney SIRT6 protein levels were significantly higher than those of lung tissue. There was also a significant difference between SIRT6 
levels of the heart versus the gastrocnemius muscle. In addition, tibialis anterior and kidney levels were significantly higher than heart SIRT6.

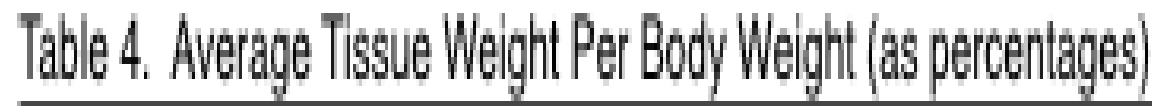

\begin{tabular}{|c|c|c|c|}
\hline & Addut l $^{1}$ & $\mathrm{Old}^{2}$ & $\begin{array}{l}\text { p.value } \\
(2+a t a l i d)\end{array}$ \\
\hline Soleuss & $0.0005 \pm 0.0042$ & $0.0710 \pm 0.0112$ & 0.0471 \\
\hline 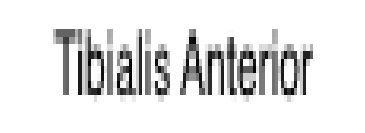 & $0.3181 \pm 0.0704$ & $0.2817 \pm 0.0417$ & 0.1549 \\
\hline Gastrocheminus $^{3}$ & $0.6067 \pm 0.0655$ & $0.4679 \pm 0.06685$ & 0.0010 \\
\hline Heast & $0.3579 \pm 0.0200$ & $0.3526 \pm 0.0535$ & 0.7980 \\
\hline Kithey & $0.5695 \pm 0.0184$ & $0.6064 \pm 0.0459$ & 0.1006 \\
\hline Lungys & $0.46883 \pm 0.0666$ & $0.4569+0.0029$ & 0.8182 \\
\hline
\end{tabular}




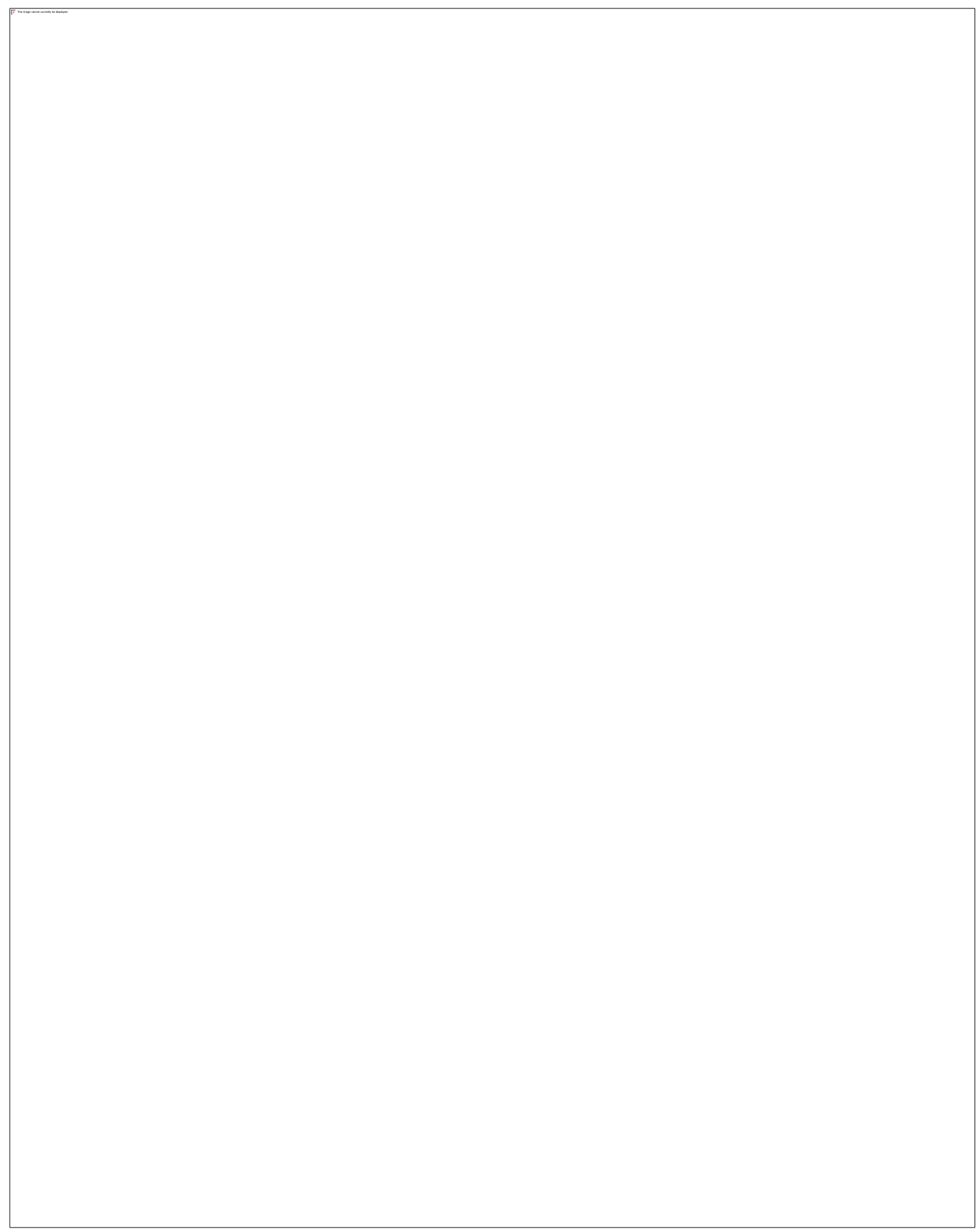


Analyses were also performed to compare the effect of age on SIRT6 protein levels in specific tissues (Figures 18 and 19). The comparisons between age groups indicated SIRT6 was not significantly different between the Old and Adult rats in any of the tissues examined (Figures 18 and 19). These data suggest that SIRT6 in rats is regulated in a tissue-specific manner. However, we did not detect age-dependent differences between tissues for SIRT6 protein levels. 


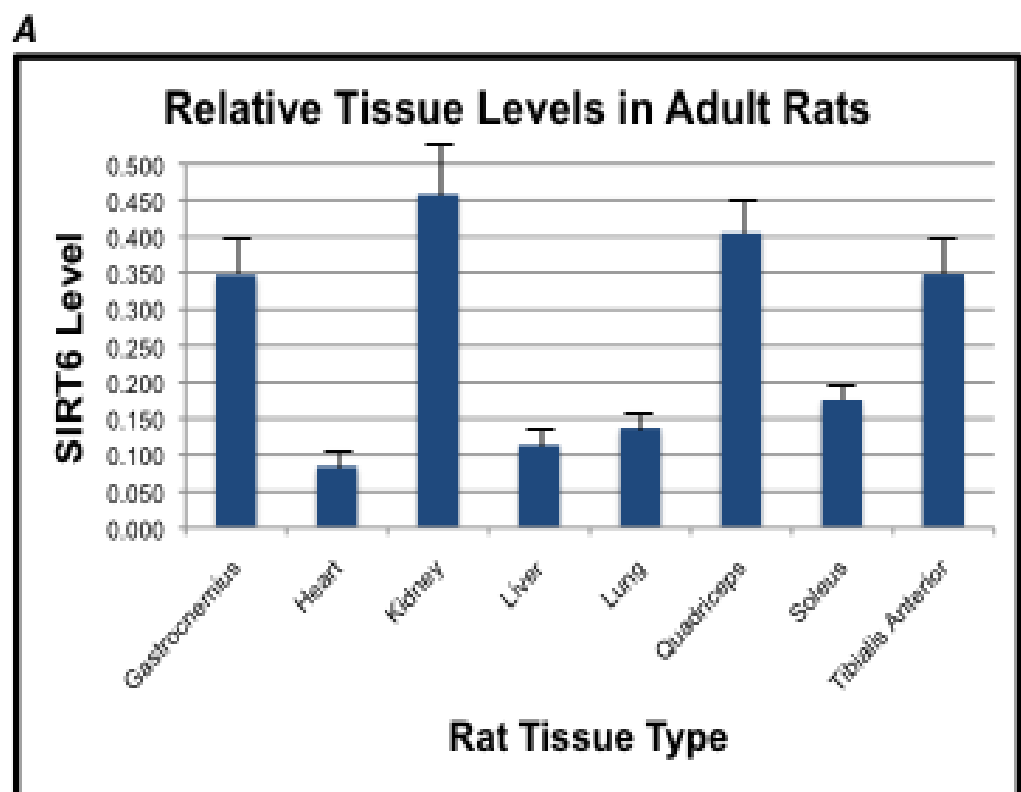

\section{B}

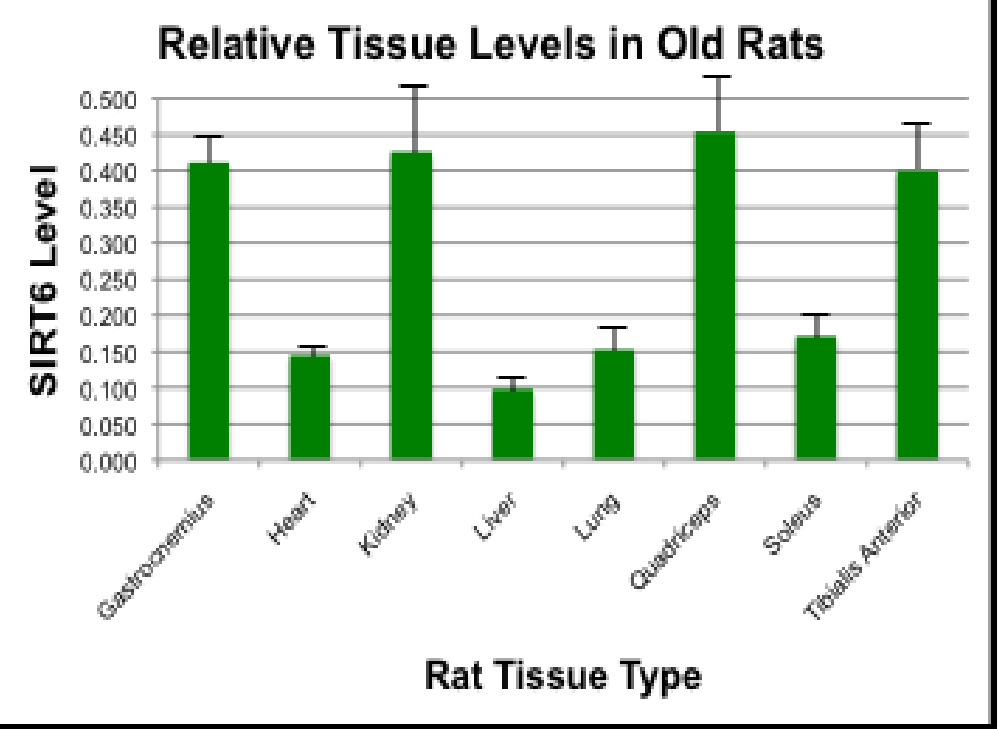

Figure 17: Tissue levels of SIRT6 in adult (age 6 months) and old (age 21 months) rats. Fifty $\mu \mathrm{g}$ of each tissue sample were separated by SDS-PAGE for Western Blot Analysis. Enhanced Chemiluminescence was used for detection and a BioRad Molecular Imager ChemiDoc System with QuantityOne Software was used for quantitation. Values represent band density after ECL of SIRT6 p65 for each, relative to a Jurkat cell nuclear extract control. Values are means $\pm S E M, n=4$. Data from each age group were analyzed using one-way ANOVA. Differences were considered significant at $\mathrm{P}<0.05$. Levels of statistically significant differences are described in the text. 
$\boldsymbol{A}$

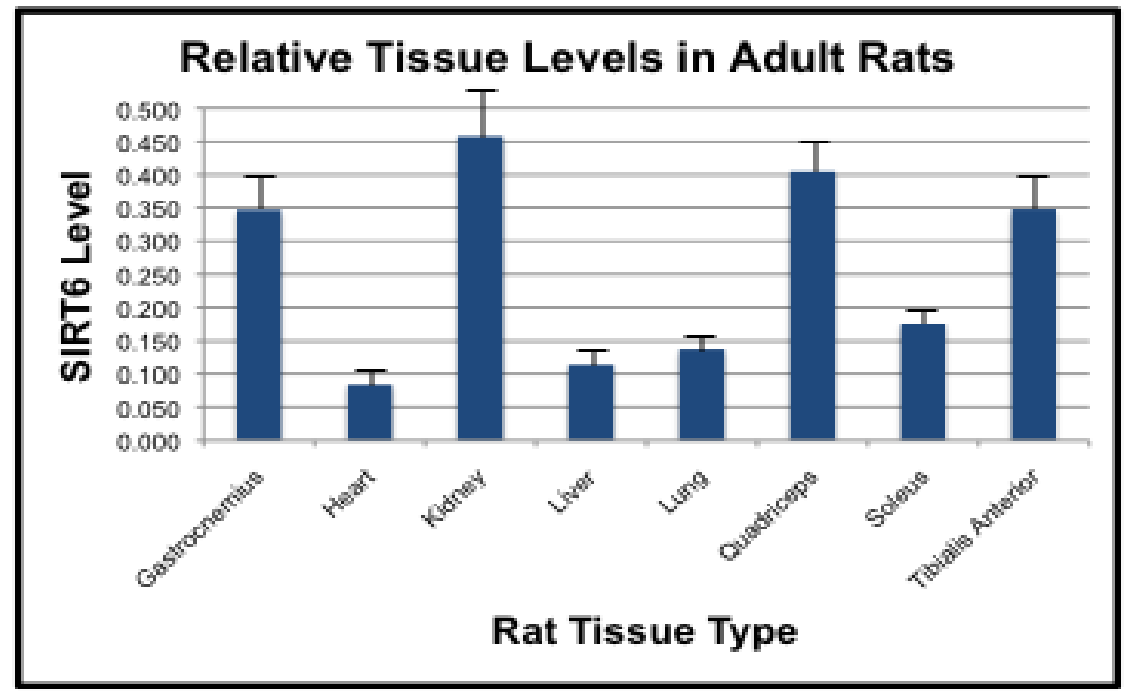

B

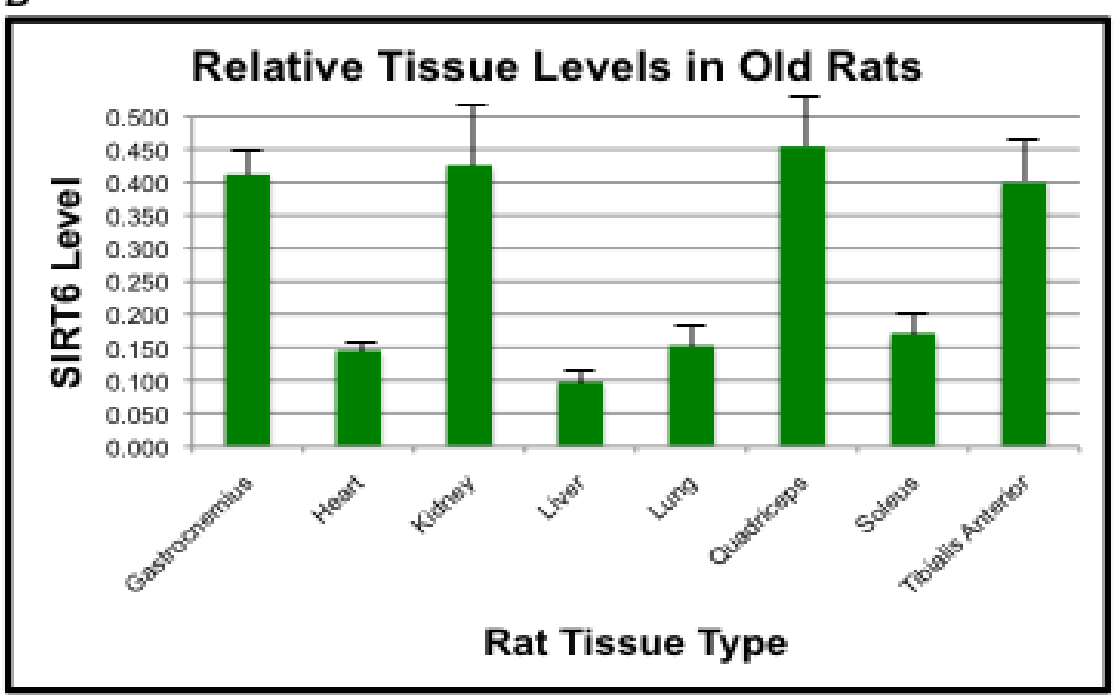

Figure 17: Tissue levels of SIRT6 in adult (age 6 months) and old (age 21 months) rats. Fifty $\mu \mathrm{g}$ of each tissue sample were separated by SDS-PAGE for Western Blot Analysis. Enhanced Chemiluminescence was used for detection and a BioRad Molecular Imager ChemiDoc System with QuantityOne Software was used for quantitation. Values represent band density after ECL of SIRT6 p65 for each, relative to a Jurkat cell nuclear extract control. Values are means $\pm S E M, n=4$. Data from each age group were analyzed using one-way ANOVA. Differences were considered significant at $\mathrm{P}<0.05$. Levels of statistically significant differences are described in the text. 


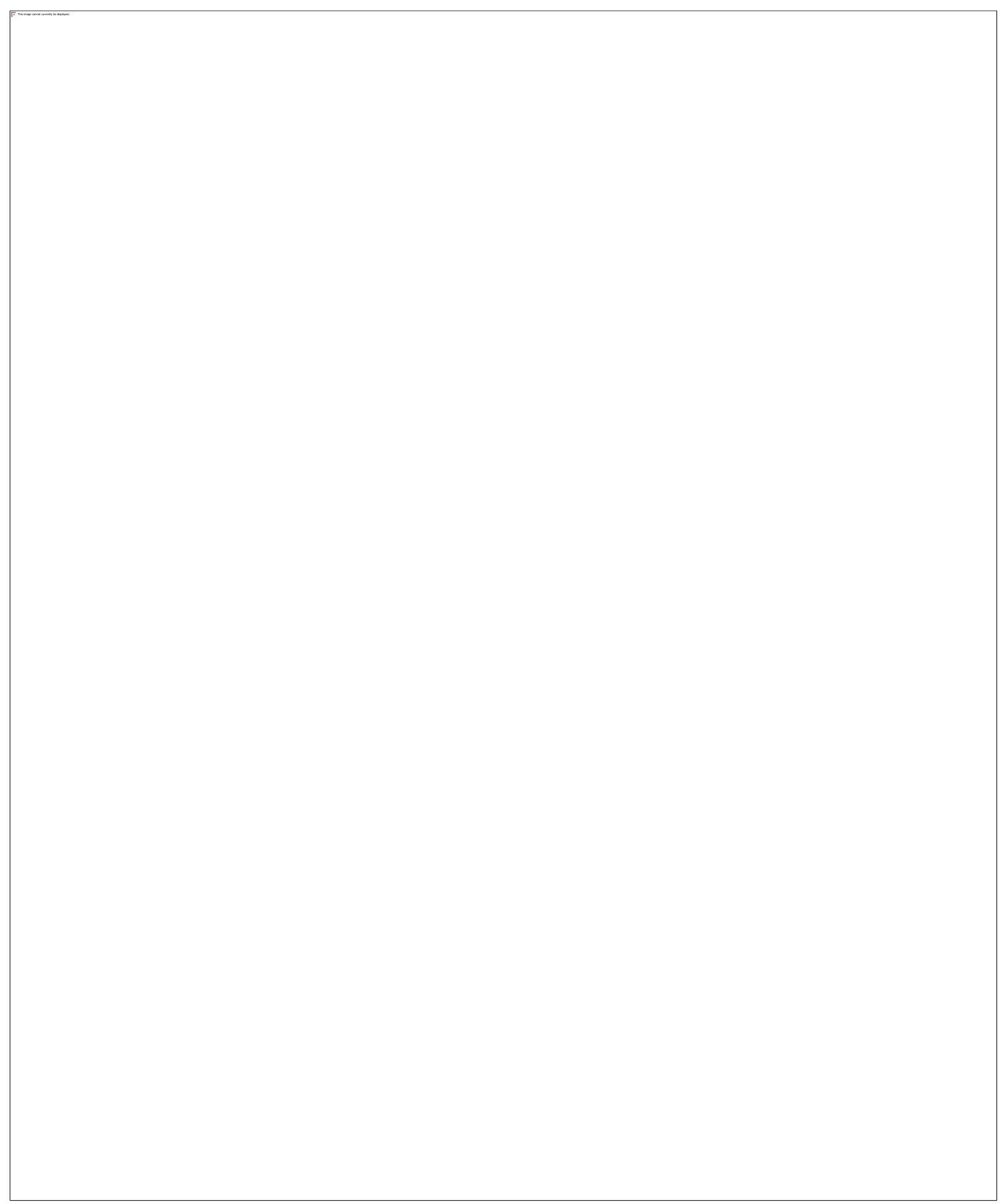




\section{DISCUSSION}

This study compared effects of aging in Adult (6-month old) and Old (21-month old) Sprague Dawley rats. The average life span of Sprague Dawley rats has been reported to be approximately 25 months (Cameron et al., 1982) so 21-months represents a stage near the end of their lifespan. We hypothesized that older rats would display increased markers of muscle cell stress and inflammation (specifically, NF-KB). To minimize potential effects of diet on these parameters, upon arrival rats consumed the same control diet for approximately three days before being fed the same experimental diet ad libitum for 10-17 days. Because of the difference in age, the Old rats had body weights that were significantly higher than the Adult rats. Although body fat was not measured, Old rats also had visibly higher amounts of body fat that was apparent during excision of tissues. The Old rats were also noticeably less active than their younger counterparts. It should be noted that the experimental diet provided had lower than recommended amounts of leucine as a means of potentially increasing proteolysis of aging. However, both groups consumed the same amount of diet per day in terms of grams.

A number of tissues including four different muscles were excised to measure their mass and their NF-KB (p65) and SIRT6 protein levels. NF-KB is a transcription factor complex that regulates a variety of genes in numerous processes including muscle proteolysis during aging. NF-kB complexes can function either as transcriptional activators or repressors depending on their specific components (Hayden and Ghosh, 2004). NF-kB containing $\mathrm{p} 65 / \mathrm{p} 50$ and $\mathrm{p} 65 / \mathrm{p} 52$ heterodimers have been found to 
function as transcriptional activators (Hayden and Ghosh, 2004) while p52/p52 and p50/p50 heterodimers function as transcriptional repressors (Li and Verma, 2002). Studies have indicated that $\mathrm{p} 65$ is a key component for up-regulating NF-KB-dependent transcription (Schmitz and Baeuerle, 1991) and that muscle p65 nuclear protein levels are increased during hindlimb immobilization in rats (Bar-Shai et al., 2005). p65 effects are also regulated by SIRT6 as the two proteins interact (Kawahara et al., 2009). We hypothesized levels of NF-KB (p65) and SIRT6 would be affected by age in specific tissues. To the best of our knowledge, we believe this is the first study to compare levels of these proteins in various tissues of Adult and Old rats.

The pattern of protein levels in tissues appeared to be quite different for NF-KB (p65) and SIRT6. We observed differences in NF-kB (p65) protein levels between tissues with the highest level being in lung although in the Adult rats differences between lung, liver, and soleus did not reach statistical significance. Tissue levels of SIRT6 had a quite different pattern from that of NF-KB (p65). There was not any single tissue that expressed significantly higher levels of SIRT6 relative to the other tissues. Instead, there appeared to be a pattern of four tissues with higher levels of SIRT6 in both age groups. The pattern of NF-kB (p65) vs. SIRT6 protein levels is different and most likely unrelated although additional studies would be needed to confirm this is the case in these tissues.

Our experiments included comparisons of NF-KB (p65) and SIRT6 between age groups in each specific tissue. In most tissues, it appeared that aging did not alter NF-кB (p65) or SIRT6 protein levels. However, NF-KB (p65) levels in the kidney and quadriceps were more than $25 \%$ higher in the Old rats vs. Adult rats although differences 
did not reach statistical significance. Interestingly, the higher level of NF-KB (p65) in gastrocnemius of Old rats was significant. The observation that the weight of gastrocnemius muscle in Old rats was significantly less than that of Adult rats raises the possibility that the elevation in NF-KB (p65) in gastrocnemius in Old rats was involved in enhanced proteolysis and loss of gastrocnemius tissue.

Tissue atrophy is commonly associated with the aging process. However, tissue atrophy can be categorized as either cachexia or sarcopenia. Cachexia is typically related to cancer and other inflammatory diseases and it can affect numerous tissues including skeletal muscle (Delano and Moldawer, 2006; Morley et al., 2006). Sarcopenia is specifically related to muscle wasting during aging (Greenlund and Nair, 2003; Thomas, 2007). Muscle atrophy through protein turnover can occur due to reduced protein synthesis, enhanced proteolysis or both (Jackman and Kandarian, 2004; Ventadour and Attaix, 2006; Eley and Tisdale, 2007). There is a diverse array of physiological stimuli that regulate protein turnover during various conditions and stages of the life cycle. In general, insulin and its signaling pathway stimulate protein synthesis and decrease proteolysis in one of the most significant regulators of muscle addition and retention. Therefore, a loss of insulin production or signaling effectiveness can have devastating effects in disease states such as diabetes or the process of aging.

Other hormones and cytokines including TNF- $\alpha$ also play a significant role in muscle loss during certain diseases, obesity and aging. Although extensive research has detailed a large number of molecules involved in tissue atrophy, the research has also shown that one of the key molecules in numerous signaling pathways and conditions is NF-кB. For example, NF-kB activation can attenuate insulin signaling thereby 
enhancing muscle loss. Increases in the cytokine TNF- $\alpha$ also increase NF-KB activity, and vice versa, in a regulatory process that also affects muscle atrophy. Unfortunately, we were not able to assess the status of insulin signaling or TNF- $\alpha$ levels in our rats in the current study but given the obesity and age of the Old rats it could very well be that both were affected and this could explain some of our findings.

Many studies have shown NF-KB regulation to be via phosphorylation-dependent activation and translocation to the nucleus for enhanced DNA-binding to promoter regions of target genes. However, we observed a significant increase in NF-кB (р65) protein levels in the whole cell lysate indicating that under certain conditions the actual protein level of NF-KB (p65) is regulated. This suggests the increase in NF-KB (p65) protein level in the Old rats corresponded with an increase in activated NF-KB (p65) protein and its dependent pathways. One such pathway is the ubiquitin proteolysis pathway, the major pathway for protein breakdown in muscle tissue. Indeed, research has shown that NF-KB binds to the promoter of murine ring finger-1 (MuRF1), an E3 ligase involved in ubiquitin conjugation and increases its expression (Cai et al., 2004). Our methods did not distinguish between cellular locations so we could not determine if the elevated NF-KB (p65) protein level in gastrocnemius of Old rats was due to an increase in cytosolic or nuclear NF-кB (p65) protein. Whatever the case, there appeared to be more functional NF-KB (p65) protein given that increased proteolysis is a plausible reason for reduced gastrocnemius mass in the Old rats.

Our observation of elevated NF-KB (p65) protein in gastrocnemius makes this a relatively unique study. Rather than measuring protein levels, numerous other studies have instead focused on the activation of NF-KB (p65) by measuring its DNA-binding 
activity. This has been done in various conditions including several models to study the effects of aging on NF-KB (p65) activation in muscle as well as other tissues. For example, Zaidi et al., (2005) reported a $\sim 10$-fold increase in NF-кB DNA binding in the liver of 24-month old rats. Although aging significantly increased DNA-binding activity there was not a concomitant increase in p65 protein levels (Zaidi et al., 2005). Similar observations were reported in the hippocampus (Kaufmann et al., 2002), cerebellum and frontal cortex (Korhonen et al., 2002) and cardiac sarcoplasm (Helenius et al., 1996) of old rats. These studies provide evidence that DNA-binding activity of NF-KB may increase even in the absence of an increase in cellular NF-kB (p65) protein levels.

Rather than measuring NF-kB (p65) activation, we chose to focus our efforts on measuring NF-кB (p65) protein levels in the context of tissue and age specific effects. There have been a few studies that reported NF-KB (p65) protein levels were elevated due to aging or other conditions. For example, Helenius et al., (2001) reported that in rat liver, aging led to increased NF-KB DNA binding activity as well as increased nuclear and cytosolic p52 and p65 protein levels. There were not age-associated changes in mRNA levels for $\mathrm{p} 52$ or $\mathrm{p} 65$, thereby suggesting gene expression was not altered by age (Helenius et al., 2001). A different study compared the effects of aging in the heart, liver, kidney and brain of both mice and rats by measuring both DNA binding and protein levels of p50, p52, and p65 NF-кB components (Helenius et al., 1996). Findings indicated aging was associated with a strong increase in NF-KB DNA binding activity in both rats and mice in all tissues studied (Helenius et al., 1996). Protein levels of p50, p52, and p65 in the cytosolic fractions were not increased by age in the old rats and mice. However, p52 protein levels in the nuclear fraction of heart and liver nuclear fraction of 
old animals significantly increased (Helenius et al., 1996). These findings suggest aging can cause a differential increase in nuclear rather than cytoplasmic levels of NF-KB protein components and this is at least partially responsible for the increase in DNA binding activity of NF-KB that usually occurs during aging. We did not separate nuclear and cytoplasmic fractions in our study but it seems likely that the increase in p65 protein in gastrocnemius was due to an increase in the nuclear fraction.

The decision to investigate SIRT6 was based on its putative role in aging and its relationship with NF-KB. Recently, elaborate studies by Mostoslavsky et al., (2006) showed that SIRT6-deficient mice are small and quickly develop significant abnormalities that include lordokyphosis, lymphopenia and significant metabolic disorders including altered glucose and IGF-1 homeostasis. In addition, they showed that SIRT6-deficient mouse cells had increased sensitivity to DNA-damaging agents (Mostoslavsky et al., 2006). Moreover, many of these characteristics in SIRT6-deficient mice are indicative of premature aging and indeed the life span of SIRT6-deficient mice is significantly reduced suggesting SIRT6 is a regulator of aging (Jia et al., 2012). A direct link between SIRT6 and aging was recently reported when Kawahara et al., (2009) described how SIRT6 downregulates NF-кB signaling by binding to $\mathrm{p} 65$ of NF-кB. This can result in deacetylation of histone $\mathrm{H} 3 \mathrm{~K} 9$ residues located in NF-KB target gene promoters and modulation of aging effects (Kawahara et al., 2009). This likely represents an important mechanism of how SIRT6 promotes longevity. Given the relevance of SIRT6 in NF-KB signaling and aging we believe our data on tissue and agespecific effects on SIRT6 protein levels provides useful information toward characterization of SIRT6. 
Our data showed SIRT6 is regulated in a tissue-specific manner. When we compared SIRT6 protein levels of Adult vs. Old rats in each of the tissues we did not observe statistically significant differences. Because of the role of SIRT6 in aging, we expected to see a decline in at least some of the tissues of the Old rats. However, it is possible that SIRT6 was affecting its downstream targets differently in Adult and Old rats in ways that did not require alterations in SIRT6 protein levels. Research in SIRT6regulated effects is still in the early stages so it has not yet been determined if changes in SIRT6 protein levels are a major point of regulation. Recent studies such as that by Kawahara et al., (2011) have provided information about transcriptional networks related to SIRT6 and as the research in SIRT6 moves forward it should become more clear as to whether or not SIRT6 protein levels are commonly altered for regulatory effects or if other mechanisms are involved in modulating SIRT6 targets.

In summary, it was found that the level of NF-KB (p65) protein was significantly higher in the gastrocnemius of Old as compared to Adult rats, and there were upward trends in some other tissues. p65 and SIRT6 protein levels were also significantly different between many of the tissues. Therefore, both NF-kB(p65) and SIRT6 were regulated in a tissue-specific manner while only NF-KB(65) was also regulated by age in specific tissues. We believe our findings provide interesting information in the potential roles of NF-KB and SIRT6 in the aging process. 


\section{CONCLUSIONS}

Recent research has examined some of the mechanisms that may be involved in sarcopenia and as a result some of the cellular molecules involved in sarcopenia and the aging process have been identified. One set of molecules that seem to play a key role in aging are known in mammals as the Sirtuins. These proteins were first identified as being related to longevity because of their role in caloric restriction and increased life span in several organisms other than humans. Although the role of Sirtuins in humans remains relatively unclear, evidence has indicated the Sirtuins regulate the expression of a large number of genes by altering chromatin structure and the activity of the Sirtuins can be affected by diet and exercise. Data from the current study indicated that SIRT6 levels were significantly different between some of the tissues examined in rats. However, it did not appear that tissue differences in SIRT6 were affected by age.

Research has also determined that a protein complex known as NF-KB plays a significant role in regulating some of the processes involved in aging. NF-KB is one of the most well-studied transcription factors because it plays a role in so many pathways in the body and it is unique because it both a sensor and signaling molecule. Evidence has shown that NF-KB responds to dietary components and exercise regimens thereby making it a potential target for strategies to minimize negative effects of aging. The data from our study indicated that p65 (NF-kB) levels were significantly different between several tissues. Findings also showed that p65 (NF-KB) was significantly higher in the gastrocnemius of old rats as compared to the adult rats suggesting age played a role in the increase.

Although the current study provided interesting results there are several items that 
should be considered when reviewing these findings and planning future studies that are similar in design and focus. One of the obvious considerations is that larger sample size numbers may have been beneficial. This may have altered results and allowed the detection of significant differences that were not evident with current sample numbers. To address this, data from the current study could be used for statistical power analysis to estimate appropriate sample size for the next set of experiments. Indeed, there appeared to be a few relatively large differences in mean values that may have reached significance if the sample size was larger.

Another potential consideration for future work would be to alter the methods of protein analysis. For Western blot analyses, blots could be stripped and probed for a control such as actin or tubulin. These proteins are often used a controls because their levels are rarely changed by treatments and provide a method to verify that the same amounts of sample protein were loaded in each gel lane and was transferred to the membranes. Additionally, more than one source of primary antibodies could also be used for Westerns to verify results were treatment or age specific rather than due to antibody binding. Although this is rarely considered necessary it could be an additional means to validate findings.

Future experiments could also take the next step by quantifying effects of p65 (NF-KB) and SIRT6 targets. For example, levels of MuRF-1 protein could be quantified because as a target of p65 (NF-KB) it would be expected that MuRF-1 would be elevated in tissues with higher p65 (NF-KB) levels. This would be a way of indicating that the higher levels of p65 (NF-KB) in gastrocnemius of old rats was causing downstream effects. Another option for future experiments would be to add methods that quantify 
activity of SIRT6 such as measuring its ability to bind the chromatin at specific locations or its binding to p65 (NF-KB). Although we measured both SIRT6 and p65 (NF-кB) protein levels we did not directly compare their levels. Perhaps this could be viewed as a weakness of our study because other studies have shown a direct interaction between the two proteins and shown that SIRT6 attenuates some p65 (NF-kB) effects. We could have possibly devised a way to compare levels of each using a statistical approach.

Alternatively, it would have been possible to compare levels had we used actin or tubulin as a control and used it to compare levels of SIRT6 and p65 (NF-kB) relative to the control in each tissue. This could be an intriguing addition to future studies. Although hindsight appears to indicate some shortcomings in our study, we still believe our data provides some interesting and worthwhile information about SIRT6 and NF-KB. 


\section{REFERENCES}

Administration on Aging. 2012. Aging statistics. Available at: http://www.aoa.gov/AoARoot/Aging_Statistics/index.aspx (accessed on July 2012). DHHS, Washington, D.C. 2012

Ahn et al. 2008. A role for the mitochondrial deacetylase sirt3 in regulating energy homeostasis. Proceedings National Academy of Sciences. 105: 14447-14452.

Ahuja N, Schwer B, Carobbio S, Waltregny D, North BJ, Castronovo V, Maechler P, Verdin E. 2007. Regulation of insulin secretion by SIRT4, a mitochondrial ADPribosyltransferase. J Biol Chem. 282:33583-92.

Alemán H, Esparza J, Ramirez FA, et al. 2011. Longitudinal evidence on the association between interleukin- 6 and C-reactive protein with the loss of total appendicular skeletal muscle in free-living older men and women. Age Ageing 40: 469e475.

Allis, D.C., Jenuwein, T., Reinberg, D., and M-L Caparros (eds). 2007. Epigenetics. Cold Spring Harbor Laboratories Press, New York.

Anderson RM, Shanmuganayagan D, Weindruch R. 2008. Caloric Restriction and Aging: Studies in Mice and Monkeys. Toxicol Pathol. 37:47-51.

Andrews RD, MacLean DA, Riechman SE. 2006. Protein intake for skeletal muscle hypertrophy with resistance training in seniors. Int J Sport Nutr Exerc Metab 16:362e372.

Anker SD, Sharma R. 2002. The syndrome of cardiac cachexia. Int J Cardiol. 85:51-66.

Artandi, S.E. 2006. Telomeres, telomerase, and human disease. N Engl J Med 355: 1195-7.

Attaix, D., and Taillandier, D. 1998. The critical role of the ubiquitin-proteasome pathway in muscle wasting in comparison to lysosomal and calcium dependent systems. Adv Mol Cell Biol 27: 235-66.

Bar-Shai, M., Carmeli, E., and Reznick, A.Z. 2005. The role of NF-kB in protein breakdown in immobilization, aging, and exercise. New York Academy of Sciences, 1057, 431-447.

Bjelakovic, G., Nikolova, D., Gluud, L.L., Simonetti, R.G., and C. Gluud. 2007. Mortality in randomized trials of antioxidant supplements for primary and secondary prevention: systematic review and meta-analysis. JAMA 297: 842-857. 
Black JC, Mosley A, Kitada T, Washburn M, Carey M. 2008. The SIRT2 deacetylase regulates autoacetylation of p300. Mol Cell. 32:449-55.

Bodine et al. 2001. Identification of ubiquitin ligases required for skeletal muscle atrophy. Science 294: 1704-1708.

Brunet, A., Sweeney, L.B., Sturgill, J.F., Chua, K.F., Greer, P.L., Lin, Y., Tran, H., Ross, S.E., Mostoslavsky, R., et al. 2004. Stress-dependent regulation of FOXO transcription factors by the SIRT1 deacetylase. Science. 303: 2011-2015.

Cai, D., Frantz, J.D., Tawa Jr., N.E., Melendez, P.A., Oh, B. -C., Lidov, H.G.W., Hasselgren, P.-O., Frontera, W.R., Lee, J., Gloss, D.J., and S.E. Shoelson. 2004.

IKKbeta/NF-kappaB activation causes severe muscle wasting in mice. Cell 119:285-298.

Cameron, T.P., Lattuada, C.P., Kornreich, M.R., and R.E. Tarone. 1982. Longevity and reproductive comparisons for male ACI and Sprague Dawley rat aging colonies. Lab Anim Sci 32: 495-499.

Canto C, Gerhart-Hines Z, Feige J, Lagouge M, Noriega L, Milne J, Elliott P, Puigserver $\mathrm{P}$, Auwerx J. 2009. AMPK regulates energy expenditure by modulating NAD+ metabolism and SIRT1 activity. Nature. 458:23.

Cases S, Smith SJ, Zheng YW, Myers HM, Lear SR, Sande E, Novak S, Collins C, Welch CB, Lusis AJ, Erickson SK, Farese RV Jr. 1998. Identification of a gene encoding an acyl CoA:diacylglycerol acyltransferase, a key enzyme in triacylglycerol synthesis. Proc. Natl Acad. Sci. USA 95, 13018-13023.

Choi Y, Yanagawa Y, Kim S, Park T. 2013. Involvement of SIRT1-AMPK signaling in the protective action of indole-3-carbinol against hepatic steatosis in mice fed a high-fat diet. J Nutr Biochem. (Article in press)

Clavel, S., Coldefy, A.S., Kurkdjian, E., Salles, J., Margaritas, I., and B. Derijard. 2006. Atrophy-related ubiquitin ligases, atrogin-1 and MuRF1 are up-regulated in aged rat tibialis anterior muscle. Mech. Ageing Devel. 127:794-801.

Combaret et al. 2005. A leucine-supplemented diet restores the defective postprandial inhibition of proteasome-dependent proteolysis in aged rat skeletal muscle. J Physiol 569: 489-99.

Costelli P, Reffo P, Penna F, Autelli R, Bonelli G, Baccino FM. 2005. Ca2+-dependent proteolysis in muscle wasting. Int J Biochem Cell Biol. 37:2134-46.

Crozier, S., Kimball, S., Emmert, S., Anthony, J., and Jefferson, L. 2005. Oral leucine administration stimulates protein synthesis in rat skeletal muscle. J Nutr. 135:376-82. 
Davis, J.M., Murphy, E.A., Carmichael, M.D., and B. Davis. 2006. Quercetin increases brain and muscle mitochondrial biogenesis and exercise tolerance. Am J Physiol Regul Integr Comp Physiol 296(4): R1071-7.

Delano, M.J., and L.L. Moldawer. 2006. The origins of cachexia in acute and chronic inflammatory diseases. Nutr Clin Pract 21: 68-81.

Du J, Wang X, Miereles C, Bailey JL, Debigare R, Zheng B. 2004. Activation of caspase-3 is an initial step triggering accelerated muscle proteolysis in catabolic conditions. J Clin Invest. 113:115-23.

Eley, H.L., and M.J. Tisdale. 2007. Skeletal muscle atrophy, a link between depression of protein synthesis and increase in degradation. J. Biol Chem 282: 7087-7097.

Evans WJ. 1995. What is sarcopenia? J Gerontol A Biol Sci Med Sci. 50A:5e8.

Fulco M and Sartorelli V. 2008. Comparing and contrasting the roles of AMPK and SIRT1 in metabolic tissues. Cell Cycle. 7:23;3669-3679.

Gisselsson D, et al. 2001. Telomere dysfunction triggers extensive DNA fragmentation and evolution of complex chromosome abnormalities in human malignant tumors. Proc Natl Acad Sci USA 98(22):12683-12688.

Glass, D. and R. Roubenoff. 2010. Recent advances in the biology and therapy of muscle wasting. Ann. N.Y. Acad. Sci. 1211: 25-36.

Greenlund, L.J., and K. S. Nair. 2003. Sarcopenia-consequences, mechanisms, and potential therapies. Mech Ageing Dev 124: 287-299.

Grumati P, Coletto L, Sabatelli P, Cescon M, Angelin A, Bertaggia E, et al. 2010. Autophagy is defective in collagen VI muscular dystrophies, and its reactivation rescues myofiber degeneration. Nat Med. 16:1313-20.

Haigis MC, Mostoslavsky R, Haigis KM, Fahie K, Christodoulou DC, Murphy AJ, Valenzuela DM, Yancopoulos GD, Karow M, Blander G, Wolberger C, Prolla TA, Weindruch R, Alt FW, Guarente L. 2006. SIRT4 inhibits glutamate dehydrogenase and opposes the effects of calorie restriction in pancreatic beta cells. Cell. 126:941-54.

Hallows, W.C., Lee, S., and J.M. Denu. 2006. Sirtuins deacetylate and activate mammalian acetyl-CoA synthetases. Proc Natl Acad Sci U S A. 103:10230-10235.

Harman, D. 1968. Free radical theory of aging: effect of free radical reaction inhibitors on the mortality rate of male LAF mice. J. Gerontol. 23: 476-482. 
Harman, D. 2006. Free radical theory of aging: an update. Annual of the New York Academy of Science 1067: 10-21.

Hayden, M.S., and S. Ghosh. 2004. Signaling to NF-kappaB. Genes Dev 18(18):21952224.

Helenius, M., Hanninen, M., Lehtinen, .S.K., and A. Salminen. 1996. Aging-induced up-regulation of nuclear binding activities of oxidative stress responsive NF-kB transcription factor in mouse cardiac muscle. J Mol Cell Cardiol 28: 487-498.

Helenius, M., Kyrylenko, S., Vehvilainen, P. and A. Salminen. 2001. Characterization of aging-associated up-regulation of constitutive nuclear factor-kappa B binding activity. Antioxidants \& Redox Signaling 3: 147-156.

Hider, R.C., Fern, E.B., and D.R. London. 1960. Relationship between intracellular amino acids and protein synthesis in the extensor digitorum longus muscle of rats. Biochem. J. 114: 171-178.

Holloszy, J.O., Smith, E.K., Vining, M., and S. Adams. 1985. Effect of voluntary exercise on longevity of rats. J. Appl. Physiol. 59: 826-831.

Holzenberger, M. et al. 2003. IGF-1 receptor regulates lifespan and resistance to oxidative stress in mice. Nature 421: 182-187.

Imai, S., Armstrong, C.M., Kaeberlein, M., and L. Guarente. 2000. Transcriptional silencing and longevity protein Sir2 is an NAD-dependent histone deacetylase. Nature 403: 795-800.

Ivy, J.M., Klar, A.J., and J.B. Hicks. 1986. Cloning and characterization of four SIR genes of Saccharomyces cerevisiae. Mol. Cell. Biol. 6: 688-702.

Jackman, R.E., and S.C. Kandarian. 2004. The molecular basis of skeletal muscle atrophy. Am J Physiol 287: C834-C843.

Janssen I, Shepard DS, Katzmarzyk PT, Roubenoff R. 2004. The healthcare costs of sarcopenia in the United States. J Am Geriatr Soc. 52:80-5.

Jia, G., Su, L., Singhai, S. and X. Liu. 2012. Emerging roles of SIRT6 on telomere maintenance, DNA repair, metabolism and mammalian aging. Mol Cell Biochem 364: $345-350$.

Kadowaki M, Kanazawa T. Amino acids as regulators of proteolysis. 2003. J Nutr. 133:2052S-6S.

Kaeberlein, M., McVey, M., and L. Guarente. 1999. The SIR2/3/4 complex and SIR2 alone promote longevity in Saccharomyces cerevisiae by two different mechanisms. Genes Dev. 13: 2570-2580. 
Kanfi, Y., Naiman, S., Amir, G., Peshti, V., Zinman, G., Nahum, L., Bar-Joseph, Z., and H.Y. Cohen. 2012. The sirtuin SIRT6 regulates lifespan in male mice. Nature 483: 218221.

Katsanos, C.S., Kobayashi, H., Sheffield-Moore, M., Aarsland, A., and W.W. Wolfe. 2006. A high proportion of leucine is required for optimal stimulation of the rate of muscle protein synthesis by essential amino acids in the elderly. Am. J. Physiol. (Endocrin. Metab.) Epub (Feb 28, 2006).

Kaufmann, J.A., Bickfore, P.C., and G. Taglialatela. 2002. Free radical-dependent changes in constitutive Nuclear factor kappa B in the aged hippocampus. Neuroreport 13: $1917-1920$.

Kawahara, T.L.A., Michishita, E., Adler, A.S., Damian, M., Berber, E., Lin, M., McCord, R.A., Ongaigui, K.C.L., Boxer, L.D., Chang, H.Y., and Chua, K.F. 2009. SIRT6 links histone $\mathrm{H} 3$ lysine 9 deacetylation to NF-kB-dependent gene expression and organismal life span. Cell, 136, 62-74.

Kawahara, T.L.A., Rapicavoli, N.A., Wu, A.R., Qu, K., Quake, S.R. and H.Y. Chang. 2011. Dynamic chromatin localization of sirt6 shapes stress- and aging-related transcriptional networks. PLoS Genet 7(6): e1002153. doi:10.1371/journal.pgen.1002153

Kendrick, A.A., Choudhury, M., Rahman, S.M., McCurdy, C.E., Friederich, M., Van Hove, J.L.K., Watson, P.A., Birdsey, N., Bao, J., Gius, D., Sack, M.N., Jing, E., Kahn, C.R., Friedman, J.E., and K.R. Jonscher. 2011. Fatty liver is associated with reduced SIRT3 activity and mitochondrial protein hyperacetylation. Biochem J 433: 505-514.

Kent, S. 1977. Can normal aging be explained by the immunologic theory? Geriatrics, 32: 111-6.

Kenyon, C.J. 2010. The genetics of ageing. Nature 464: 504-512.

Kilberg, M.S., Shan, J., and Su, N. 2009. ATF4-dependent transcription mediates signaling of amino acid limitation. Trends Endocrinology Metab 20(9): 436-443.

Kim SC, Sprung R, Chen Y, Xu Y, Ball H, Pei J, Cheng T, Kho Y, Xiao H, Xiao L, Grishin NV, White M, Yang XJ, Zhao Y. 2006. Substrate and functional diversity of lysine acetylation revealed by a proteomics survey. Mol Cell. 23:607-18.

Kimball, S., and Jefferson, L. 2001. Regulation of protein synthesis by branched-chain amino acids. Curr Opin Clin Nutr Metab Care. 4:39-43.

Kimball, S., and Jefferson, L.S. 2006. New functions for amino acids: effects on gene transcription and translation. Am J Clin Nutr 83(suppl): 500S-507S. 
Kley RA, Vorgerd M, Tarnopolsky MA. 2007. Creatine for treating muscle disorders. Cochrane Database Syst Rev. 1:CD004760.

Klitgaard H, Mantoni M, Schiaffino S, et al. 1990. Function, morphology and protein expression of ageing skeletal muscle: A cross-sectional study of elderly men with different training backgrounds. Acta Physiol Scand. 140:41e54.

Knutson, M. and C. Leeuwenburgh. 2008. Resveratrol and novel potent activators of SIRT1: effects on aging and age-related diseases. Nutrition Reviews 66(10): 591-596.

Korhonen, P., Helenius, M., and A. Salminen. 1997. Age-related changes in the regulation of transcription factor NF-kappa G in rat brain. Neurocsci Lett 225: 61-64.

Kortebein P, Ferrando A, Lombeida J, et al. 2007. Effect of 10 days of bed rest on skeletal muscle in healthy older adults. JAMA 297:1772e1774.

Lanza, I., Short, D., Short, K., Raghavakaimal, S., Basu, R., Joyner, M., McConnel, J., and K.S. Nair. 2008. Endurance exercise as a countermeasure for aging. Diabetes 57: 2933-2942.

Layman, D. and Walker, D. 2006. Potential importance of leucine in treatment of obesity and the metabolic syndrome. J. Nutr. 136: 319S-323S.

Lee, P.D., Giudice, L.C., Conover, C.A., and D.R. Powell. 1997. Insulin-like growth factor binding protein-1: recent findings and new directions. Proc. Soc. Exp. Biol. Med. 216: 319-327.

Li, et al. 2003. Hydrogen peroxide stimulates ubiquitin-conjugating activity and expression of genes for specific E2 and E3 proteins in skeletal muscle myotubes. Am J Physiol. Cell Physiol. 285: C806-C812.

Li, H., Malhotra, S., and Kumar, A. 2008. Nuclear factor kappa-B signaling in skeletal muscle atrophy. J Mol Med (Berl). 86(10): 1113-26.

Li, Q., and I.M. Verma. 2002. NF-kappaB regulation in the immune system. Nat Rev Immunol 2(10):725-734.

Lin, S.J., Defossez, P.A., and L. Guarente. 2000. Requirement of NAD and SIR2 for life-span extension by calorie restriction in Saccharomyces cerevisiae. Science 289: $2126-2128$.

Lombard DB, Alt FW, Cheng HL, Bunkenborg J, Streeper RS, Mostoslavsky R, Kim J, Yancopoulos G, Valenzuela D, Murphy A, et al. 2007. Mammalian Sir2 homolog SIRT3 regulates global mitochondrial lysine acetylation. Mol Cell Biol. 27:8807-8814. 
Lum, J.J., Bui, T., Gruber, M., Gordan, J.D., DeBerardinis, R.J., Covello, K.L., Simon, M.C., and Thompson, C.B. 2007. The transcription factor HIF-1alpha plays a critical role in the growth factor-dependent regulation of both aerobic and anaerobic glycolysis. Genes Dev. 21, 1037-1049.

Malafarina V, Uriz-Otano F, Iniesta R, Gil-Guerrero L. 2012. Sarcopenia in the elderly: Diagnosis, physiopathology and treatment. Maturitas. 71:109e114.

Mammucari C, Milan G, Romanello V, Masiero E, Rudolf R, Del Piccolo P, et al. 2007. FoxO3 controls autophagy in skeletal muscle in vivo. Cell Metab. 6:458-71.

Mao Z, et al. 2011. SIRT6 promotes DNA repair under stress by activating PARP1. Science 332(6036):1443-1446

Marino G, Uria JA, Puente XS, Quesada V, Bordallo J, Lopez-Otin C. 2003. Human autophagins, a family of cysteine proteinases potentially implicated in cell degradation by autophagy. J Biol Chem. 278:3671-8.

McCay, C.M., Maynard, L.A., Sperling, G. and L.L. Barnes. 1939. Retarded growth, lifespan, ultimate body size and age changes in the albino rat after feeding diets restricted in calories. J Nutr 18:1-13.

McClintock B. 1941. The stability of broken ends of chromosomes in Zea mays. Genetics 26(2):234-282

McCord RA, et al. 2009. SIRT6 stabilizes DNA-dependent protein kinase at chromatin for DNA double-strand break repair. Aging (Albany NY) 1(1):109-121

Meeker AK, et al. 2004. Telomere length abnormalities occur early in the initiation of epithelial carcinogenesis. Clin Cancer Res 10(10):3317-3326

Melton 3rd LJ, Khosla S, Crowson CS, O’Fallon WM, Riggs BL. 2000. Epidemiology of sarcopenia. J Am Geriat Soc. 48:625-30.

Metoyer and Pruitt. 2008. The role of sirtuin proteins in obesity. Pathophysiology 15(2); August; 103-108.

Michishita E, et al. 2008. SIRT6 is a histone H3 lysine 9 deacetylase that modulates telomeric chromatin. Nature 452(7186): 492-496

Michishita E, et al. 2009. Cell cycle-dependent deacetylation of telomeric histone H3 lysine K56 by human SIRT6. Cell Cycle 8(16):2664-2666

Miller III, E.R., Pastor-Barriuso, R., Dalal, D., Riemersma, R.A., Appel, L.J., and E. Guallar. 2005. Meta-analysis: high-dosage vitamin E supplementation may increase 
allcause mortality. Ann. Intern. Med. 142: 37-46.

Mitch WE, Price SR. 2001. Transcription factors and muscle cachexia: is there a therapeutic target? Lancet. 357:734-5.

Mitsui, A., Hamuro, J., Nakamura, H., Kondo, N., Hirabayashi, Y., Ishizaki-Koizumi, S., Hirakawa, T., Inoue, T., and J. Yodoi. 2002. Overexpression of human thioredoxin in transgenic mice controls oxidative stress and life span. Antioxid. Redox Signal. 4: 693-696.

Moresi V, Presterá A, Scicchitano BM, Molinaro M, Teodori L, Sassoon D, et al. 2008. Tumor necrosis factor-alpha inhibition of skeletal muscle regeneration is mediated by a caspase-dependent stem cell response. Stem Cells. 26:997-1008.

Morley, J.E., Thomas, D.R., and M.-M. Wilson. 2006. Cachexia: pathophysiology and clinical relevance. Am J Clin Nutr 831 :735-743.

Mostoslavsky, R., Chua, K.F., Lombard, D.B., Pang, W.W., Fischer, M.R., Gellon, L., Liu, P., Mostoslavsky, G., Franco, S., Murphy, M.M., Mills, K.D., Patel, P., Hsu, J.T., Hong, A.L., Ford, E., Cheng, H.L., Kennedy, C., Nunez, N., Bronson, R., Frendewey, D., Auerbach, W., Valenzuela, D., Karow, M., Hottiger, M.O., Hursting, S., Barrett, J.C., Guarente, L., Mulligan, R., Demple, B., Yancopoulos, G.D., and F.W. Alt. 2006. Genomic instability and aging-like phenotype in the absence of mammalian SIRT6. Cell 124(2):315-29.

Multani AS, Chang S. 2007. WRN at telomeres: implications for aging and cancer. J Cell Sci 120(Pt 5):713-721

Muscaratoli M, Anker SD, Argilés J, et al. 2010. Consensus definition of sarcopenia, cachexia and pre-cachexia: Joint document elaborated by Special Interest Groups (SIG) "cachexia-anorexia in chronic wasting disease" and nutrition in geriatrics. Clin Nutr. 29:154e159.

Nakagawa T, Lomb DJ, Haigis MC, Guarente L. 2009. SIRT5 Deacetylates carbamoyl phosphate synthetase 1 and regulates the urea cycle. Cell. 137:560-70.

Nakamura, E., Moritani, T., and A. Kanetaka. 1996. Effects of habitual physical exercise on physiological age in men aged 20-85 years as estimated using principal component analysis. Eur. J. Appl. Physiol. Occup. Physiol. 73: 410-418.

Nakashima, K., Ishida, A., Yamazaki, M., and Abe, H. 2005. Leucine suppresses myofibrillar proteolysis by down-regulating ubiquitin-proteasome pathway in chick skeletal muscles. Biochem Biophys Res Commun 336(2): 660-6.

Nakashima, et al. 2006. Leucine suppresses myofibrillar proteolysis by down-regulating ubiquitin-proteasome pathway in chick skeletal muscles. Biochem Biophys Research Commun 336: 660-665. 
Nasrin N, Wu X, Fortier E, Feng Y, Bare OC, Chen S, Ren X, Wu Z, Streeper RS, Bordone L. 2010. SIRT4 regulates fatty acid oxidation and mitochondrial gene expression in liver and muscle cells. J Biol Chem. 285:31995-2002.

Natoli, G. 2009. When sirtuins and NF-кB collide. Cell 136: 19-21.

Navarro, A., Gomez, C., Lopez-Cepero, J.M., and A. Boveris. 2004. Beneficial effects of moderate exercise on mice aging: survival, behavior, oxidative stress, and mitochondrial electron transfer. Am. J. Physiol. Regul. Integr. Comp. Physiol. 286: R505-R511.

Nissen, S., Sharp, R., Ray, M., Rathmacher, J., Rice, D., Fuller, J., Connelly, S., and Abumrad, N. 1996. Effects of leucine metabolite $\beta$-hydroxy- $\beta$-methylbutyrate on muscle metabolism during resistance-exercise training. J. Apply. Physiol. 81(5): 20952104.

Ogata T, Oishi Y, Higuchi M, Muraoka I. 2010. Fasting-related autophagic response in slow-and fast-twitch skeletal muscles. Biochem Biophys Res Commun. 394:136-40.

O’Leary MFN, Hood DA. 2009. Denervation-induced oxidative stress and autophagy signaling in muscle. Autophagy. 5:230-1.

Palacios, O.M., Carmona, J.J., Michan, S., Chen, K.Y., Manabe, Y., Ward, J.L. 3rd, Goodyear, L.J., Q. Tong. 2009. Diet and exercise signals regulate SIRT3 and activate AMPK and PGC-1alpha in skeletal muscle. Aging 1: 771-83.

Pawelec, G., Akbar, A., Caruso, C., Effros, R., Grubeck-Loebenstein, B., and Wikby, A. 2004. Is immunosenescence infectious? Trends Immunol 25:406-410.

Perez, V.I., Van, R.H., Bokov, A., Epstein, C.J., Vijg, J., and A. Richardson. 2009. The overexpression of major antioxidant enzymes does not extend the lifespan of mice. Aging Cell 8: 73-75.

Pillai, V.B., Sundaresan, N.R., Kim, G., Gupta, M., Rajamohan, S.B., Pillai, J.B., Samant, S., Ravindra, P.V., Isbatan, A., and M.P. Gupta. 2010. Exogenous NAD blocks cardiac hypertrophic response via activation of the SIRT3-LKB1-AMP-activated kinase pathway. J Biol. Chem. 285: 3133-44.

Powers, S.K., and M.J. Jackson. 2008. Exercise-induced oxidative stress: cellular Mechanisms and impact on muscle force production. Physiol Rev. 88: 1243-1276.

Price N, Gomes A, Ling A, Duarte F, Martin-Montalve A, North B, et al. 2012. SIRT1 is required for AMPK activation and the beneficial effects of resveratrol on mitochondrial function. Cell Metab 15:675-690. 
Rine, J. and I. Herskowitz. 1987. Four genes responsible for a position effect on expression from HML and HMR in Saccharomyces cerevisiae. Genetics 116: 9-22.

Rodgers, J.T., Lerin, C., Haas, W., Gygi, S.P., Spiegelman, B.M., and P. Puigserver. 2005. Nutrient control of glucose homeostasis through a complex of PGC-1alpha and SIRT1. Nature 434: 113-118.

Rosenberg IH. 1997. Sarcopenia: Origins and clinical relevance. J Nutr. 127(5 Suppl):990Se991S.

Sadiq et al. 2007. Amino acids and insulin act additively to regulate components of the ubiquitin-proteasome pathway in $\mathrm{C} 2 \mathrm{C} 12$ myotubes. BMC Molecular Biol 8(23).

Salminen, A., Huuskonen, J., Ojala, J., Kauppinen, A., Kaarniranta, K., and T. Suuronen. 2008. Activation of innate immunity system during aging: NF-kB signaling is the molecular culprit of inflamm-aging. Ageing Res Reviews 7: 83-105.

Scher MB, Vaquero A, Reinberg D. 2007. SirT3 is a nuclear NAD+-dependent histone deacetylase that translocates to the mitochondria upon cellular stress. Genes Dev. 21:920-928.

Schlicker C, Gertz M, Papatheodorou P, Kachholz B, Becker CF, Steegborn C. 2008. Substrates and regulation mechanisms for the human mitochondrial sirtuins Sirt3 and Sirt5. J Mol Biol. 382:790-801.

Schmitz, M.L., and P.A. Baeuerle. 1991. The p65 subunit is responsible for the strong transcription activating potential of NF-kappa B. EMBO J 10(12):3805-3817.

Schriner, S.E., Linford, N.J., Martin, G.M., Treuting, P., Ogburn, C.E., Emond, M., Coskun, P.E., Ladiges, W., Wolf, N., Van Remmen, H., Wallace, D.C., and P.S.

Rabinovitch. 2005. Extension of murine lifespan by overexpression of catalase targeted to mitochondria. Science 308: 1909-1911.

Schwer B, Eckersdorff M, Li Y, Silva JC, Fermin D, Kurtev MV, Giallourakis C, Comb MJ, Alt FW, Lombard DB. 2009. Calorie restriction alters mitochondrial protein acetylation. Aging Cell. 8:604-6.

Seagroves, T.N., Ryan, H.E., Lu, H., Wouters, B.G., Knapp, M., Thibault, P., Laderoute, K., and Johnson, R.S. 2001. Transcription factor HIF-1 is a necessary mediator of the pasteur effect in mammalian cells. Mol. Cell. Biol. 21, 3436-3444.

Shi, T., Wang, F., Stieren, E., and Q. Tong. 2005. SIRT3, a mitochondrial sirtuin deacetylase, regulates mitochondrial function and thermogenesis in brown adipocytes. J Biol. Chem. 280: 13560-7. 
Smith, H., Mukerji, P., and Tisdale, M. 2005. Attenuation of proteasome-induced proteolysis in skeletal muscle by $\{$ beta $\}$-hydroxy-\{beta $\}$-methylbutyrate in cancerinduced muscle loss. Cancer Res. 65(1):277-83.

Smith IJ, Dodd SL. 2007. Calpain activation causes a proteasome-dependent increase in protein degradation and inhibits the Akt signaling pathway in rat diaphragm muscle. Exp Physiol. 92:561-73.

Taylor, et al. 2008. Biological and potential therapeutic roles of sirtuin deacetylases. Cellular and Molecular Life Sciences 65: 4000-4018.

Thomas, C.R. 2007. Loss of skeletal muscle mass in aging: examining the relationship of starvation, sarcopenia and cachexia. Clin Nutr 26: 389-399.

Troen, B. 2003. The biology of aging. Mount Sinai Journal of Medicine 70: 3-22.

U.S. Department of Health and Human Services. 2008. Physical Activity Guidelines for Americans. Chapter 5: Active Older Adults. Retrieved from http://www.health.gov/paguidelines/guidelines/chapter5.aspx

Vaziri, H., and S. Benchimol. 1998. Reconstitution of telomerase activity in normal human cells leads to elongation of telomeres and extended replicative life span. Curr Biol 8: 279-82.

Ventadour, S., and D. Attaix. 2006. Mechanisms of skeletal muscle atrophy. Curr Opin Rheumatol 18: 631-635.

Visser M, Pahor M, Taaffe DR, et al. 2002. Relationship of interleukin-6 and tumor necrosis factor-alpha with muscle mass and muscle strength in elderly men and women: The Health ABC Study. J Gerontol A Biol Sci Med Sci. 57: M326eM332.

von Haehling S, Morley JE, Anker SD. 2010. An overview of sarcopenia: facts and numbers on prevalence and clinical impact. J Cachexia Sarcopenia Muscle. 1:129-33.

Walford RL. 1969. The Immunologic theory of aging. Munksgaard, Copenhagen.

Wolfe RR, Miller SL, Miller KB. 2008. Optimal protein intake in the elderly. Clin Nutr. 27:675e684.

Yeung, F., Hoberg, J., Ramsey, C., Keller, M., Jones, D., Frye, R., and M. Mayo. 2004. Modulation of NF-kappaB-dependent transcription and cell survival by the SIRT1 deacetylase. EMBO J. 23: 2369-2380.

Yoshida K, Shimizugawa T, Ono M, Furukawa H. 2002. Angiopoietinlike protein 4 is a potent hyperlipidemia-inducing factor in mice and inhibitor of lipoprotein lipase. J. Lipid 
Res. 43, 1770-1772.

Zaidi, G., Panda, H., and P.C. Supakar. 2005. Increased phosphorylation and decreased level of IkBx during aging in rat liver. Biogerontology 6: 141-145.

Zhao S, Xu W, Jiang W, Yu W, Lin Y, Zhang T, Yao J, Zhou L, Zeng Y, Li H, Li Y, Shi J, An W, Hancock SM, He F, Qin L, Chin J, Yang P, Chen X, Lei Q, Xiong Y, Guan KL. 2010. Regulation of cellular metabolism by protein lysine acetylation. Science.

327:1000-4.

Zhong, L., D'Urso, A., Toiber, D., Sebastian, C., Henry, R.E., Vadysirisack, D.D., Guimaraes, A., Marinelli, B., Wikstrom, J.D., Nir, T., Clish, C.B., Vaitheesvaran, B., Iliopoulos, O., Kurland, I., Dor, Y., Weissleder, R., Shirihai, O.S., Ellisen, L.W., Espinosa, J.M., and R. Mostoslavsky. 2010. The histone deacetylase sirt6 regulates glucose homeostasis via hif1 $\alpha$. Cell 140(2): 280-93. 